Atmos. Chem. Phys., 19, 11911-11937, 2019

https://doi.org/10.5194/acp-19-11911-2019

(C) Author(s) 2019. This work is distributed under

the Creative Commons Attribution 4.0 License.

\title{
MICS-Asia III: multi-model comparison and evaluation of aerosol over East Asia
}

Lei Chen ${ }^{1,2,6}$, Yi Gao ${ }^{1}$, Meigen Zhang ${ }^{1,3,4}$, Joshua S. Fu ${ }^{5}$, Jia Zhu ${ }^{2,6,7}$, Hong Liao ${ }^{2,6}$, Jialin Li $^{1}$, Kan Huang ${ }^{5}$, Baozhu Ge ${ }^{1}$, Xuemei Wang ${ }^{8}$, Yun Fat Lam ${ }^{9}$, Chuan-Yao Lin ${ }^{10}$, Syuichi Itahashi ${ }^{11,12}$, Tatsuya Nagashima ${ }^{13}$, Mizuo Kajino ${ }^{14,15}$, Kazuyo Yamaji ${ }^{16}$, Zifa Wang ${ }^{1,3}$, and Jun-ichi Kurokawa ${ }^{17}$

${ }^{1}$ State Key Laboratory of Atmospheric Boundary Layer Physics and Atmospheric Chemistry, Institute of Atmospheric Physics, Chinese Academy of Sciences, Beijing, China

${ }^{2}$ School of Environmental Science and Engineering,

Nanjing University of Information Science \& Technology, Nanjing, China

${ }^{3}$ University of Chinese Academy of Sciences, Beijing, China

${ }^{4}$ Center for Excellence in Regional Atmospheric Environment, Institute of Urban Environment, Chinese Academy of Sciences, Xiamen, China

${ }^{5}$ Department of Civil and Environmental Engineering, University of Tennessee, Knoxville, TN, USA

${ }^{6}$ Jiangsu Key Laboratory of Atmospheric Environment Monitoring and Pollution Control, Jiangsu Collaborative Innovation

Center of Atmospheric Environment and Equipment Technology, Nanjing University of Information Science \& Technology, Nanjing, China

${ }^{7}$ Research Institute of Climatic and Environmental Governance, Nanjing University of Information Science \& Technology,

Nanjing, China

${ }^{8}$ Institute for Environment and Climate Research, Jinan University, Guangzhou, China

${ }^{9}$ School of Energy and Environment, City University of Hong Kong, Hong Kong SAR, China

${ }^{10}$ Research Center for Environmental Changes, Academia Sinica, Taipei, Taiwan

${ }^{11}$ Central Research Institute of Electric Power Industry, Abiko, Chiba, Japan

${ }^{12}$ Department of Marine, Earth, and Atmospheric Sciences, North Carolina State University, Raleigh, NC, USA

${ }^{13}$ National Institute for Environmental Studies, Tsukuba, Japan

${ }^{14}$ Meteorological Research Institute, Japan Meteorological Agency, Tsukuba, Japan

${ }^{15}$ Faculty of Life and Environmental Sciences, University of Tsukuba, Tsukuba, Japan

${ }^{16}$ Graduate School of Maritime Sciences, Kobe University, Kobe, Hyogo, Japan

${ }^{17}$ Asia Center for Air Pollution Research, 1182 Sowa, Nishi-ku, Niigata, Niigata, Japan

Correspondence: Meigen Zhang (mgzhang@mail.iap.ac.cn)

Received: 25 December 2018 - Discussion started: 11 February 2019

Revised: 4 June 2019 - Accepted: 14 August 2019 - Published: 25 September 2019

\begin{abstract}
A total of 14 chemical transport models (CTMs) participated in the first topic of the Model Inter-Comparison Study for Asia (MICS-Asia) phase III. These model results are compared with each other and an extensive set of measurements, aiming to evaluate the current CTMs' ability in simulating aerosol concentrations, to document the similarities and differences among model performance, and to reveal the characteristics of aerosol components in large cities over East Asia. In general, these CTMs can well repro-
\end{abstract}

duce the spatial-temporal distributions of aerosols in East Asia during the year 2010. The multi-model ensemble mean (MMEM) shows better performance than most single-model predictions, with correlation coefficients (between MMEM and measurements) ranging from 0.65 (nitrate, $\mathrm{NO}_{3}^{-}$) to 0.83 $\left(\mathrm{PM}_{2.5}\right)$. The concentrations of black carbon (BC), sulfate $\left(\mathrm{SO}_{4}^{2-}\right)$, and $\mathrm{PM}_{10}$ are underestimated by MMEM, with normalized mean biases (NMBs) of $-17.0 \%,-19.1 \%$, and $-32.6 \%$, respectively. Positive biases are simulated for $\mathrm{NO}_{3}^{-}$ 
$(\mathrm{NMB}=4.9 \%)$, ammonium $\left(\mathrm{NH}_{4}^{+}\right)(\mathrm{NMB}=14.0 \%)$, and $\mathrm{PM}_{2.5}(\mathrm{NMB}=4.4 \%)$. In comparison with the statistics calculated from MICS-Asia phase II, frequent updates of chemical mechanisms in CTMs during recent years make the intermodel variability of simulated aerosol concentrations smaller, and better performance can be found in reproducing the temporal variations of observations. However, a large variation (about a factor of 2) in the ratios of SNA (sulfate, nitrate, and ammonium) to $\mathrm{PM}_{2.5}$ is calculated among participant models. A more intense secondary formation of $\mathrm{SO}_{4}^{2-}$ is simulated by Community Multi-scale Air Quality (CMAQ) models, because of the higher SOR (sulfur oxidation ratio) than other models ( 0.51 versus 0.39$)$. The NOR (nitric oxidation ratio) calculated by all CTMs has larger values $(\sim 0.20)$ than the observations, indicating that overmuch $\mathrm{NO}_{3}^{-}$is simulated by current models. $\mathrm{NH}_{3}$-limited condition (the mole ratio of ammonium to sulfate and nitrate is smaller than 1) can be successfully reproduced by all participant models, which indicates that a small reduction in ammonia may improve the air quality. A large coefficient of variation $(\mathrm{CV}>1.0)$ is calculated for simulated coarse particles, especially over arid and semi-arid regions, which means that current CTMs have difficulty producing similar dust emissions by using different dust schemes. According to the simulation results of MMEM in six large Asian cities, different air-pollution control plans should be taken due to their different major air pollutants in different seasons. The MICSAsia project gives an opportunity to discuss the similarities and differences of simulation results among CTMs in East Asian applications. In order to acquire a better understanding of aerosol properties and their impacts, more experiments should be designed to reduce the diversities among air quality models.

\section{Introduction}

Urbanization and industrialization have stimulated economic growth and population expansion during the last several decades in East Asia (Spence et al., 2008; Yan et al., 2016; Chen et al., 2016) but also brought about noticeable degradation of ecological environment at the same time (Hall, 2002; Han et al., 2014; Yue et al., 2017). Significant increase in atmospheric aerosol loading, especially from anthropogenic emissions, can exert adverse effects on weather (Cowan et al., 2013), climate (H. Wang et al., 2016), air quality (Y. Gao et al., 2016), and human health (Carmichael et al., 2009). For example, aerosols can modify the thermodynamic structure of the atmospheric boundary layer by absorbing and scattering solar radiation (Ding et al., 2016; Petaja et al., 2016), alter cloud properties and precipitation, by acting as cloud condensation nuclei and ice nuclei (Lohmann and Diehl, 2006; Wang, 2013), deteriorate visibility, and cause haze events (Singh and Dey, 2012; Li et al., 2014). In addition, fine particulate matter with aerodynamic diameters smaller than $2.5 \mu \mathrm{m}\left(\mathrm{PM}_{2.5}\right)$ may enter into the alveoli and cause severe cardiovascular diseases, respiratory diseases, and even lung cancer (Pope and Dockery, 2006; M. Gao et al., 2015). The impacts have attracted considerable attention from the public and policy makers in East Asia, and therefore the research on aerosol has become a hot topic during recent years.

In order to better understand the properties of atmospheric aerosols and their impacts, chemical transport models (CTMs) can be a critical tool, and they have been applied to study various air-pollution issues all over the world. For example, a fully coupled online Weather Research and Forecasting model with chemistry (WRF-Chem) was developed by Grell et al. (2005), and it has been widely used to study the aerosol-radiation-cloud feedbacks on meteorology and air quality (Gao et al., 2014; B. Zhang et al., 2015; Qiu et al., 2017); a Community Multi-scale Air Quality (CMAQ) modeling system was designed by the US Environmental Protection Agency (Byun and Ching, 1999), and it has been applied to address acid deposition, visibility and haze pollution issues (Zhang et al., 2006; Han et al., 2014; Fan et al., 2015); a nested air quality prediction model system (NAQPMS) was developed by the Institute of Atmospheric Physics, Chinese Academy of Science (IAP/CAS) (Wang et al., 2001) to reproduce the mechanism of transport and evolution of atmospheric pollutants in Asia ( $\mathrm{Li}$ et al., 2012; Z. Wang et al., 2013; J. Li et al., 2017); a global three-dimensional chemical transport model (GEOS-Chem) was first presented by Bey et al. (2001), and researchers use the GEOS-Chem model to study the source sector contribution, long-range transport, and the prediction of future change in ozone and aerosol concentrations (Liao et al., 2006; K. Li et al., 2016b; Zhu et al., 2017).

Although significant advantages can be found in CTMs, how to accurately reproduce or predict the concentrations and the distributions of atmospheric pollutants is still a challenge, with the problems of inaccurate emission inventories, poorly represented initial and boundary conditions, and imperfect physical, dynamical, and chemical parameterizations (Carmichael et al., 2008). Meanwhile, most CTMs are designed to focus on the air quality over developed countries, such as Europe and America, rather than Asia. The assumptions or look-up tables used in CTMs may not be suitable for the simulations of the East Asian environment (Gao et al., 2018). Therefore, before providing meaningful results and answering "what if" questions for policy makers, model performance must be carefully evaluated. Hayami et al. (2008) and Mann et al. (2014) pointed out that different parameterizations used in CTMs can cause large variations in simulation results, and the multi-model ensemble mean (MMEM) tends to show better performance than most single-model predictions when compared with observations (Carmichael et al., 2002; Hayami et al., 2008; Wang et al., 2008; Holloway et al., 2008). In order to develop a better common understanding of the performance and uncertainties of CTMs in East 
Asian applications, and to acquire a more mature comprehension of the properties of atmospheric aerosols and their impacts, a model intercomparison study should be initiated, and Model Inter-Comparison Study for Asia (MICS-Asia) gives an opportunity to investigate these questions. Meanwhile, model intercomparison study in East Asia is very limited (Phadnis et al., 1998; Kiley et al., 2003; Han et al., 2008), and far more efforts are needed in the future.

The MICS-Asia project was initiated in 1998. In the first phase of MICS-Asia (MICS-Asia phase I), the primary target was to study the long-range transport and deposition of $\mathrm{SO}_{4}^{2-}$ in East Asia by analyzing the submitted simulation results from eight CTMs. Source-receptor relationships, contributions from removal processes, and the influences of model structures and parameterizations on simulation results were also estimated. More details can be found in Carmichael et al. (2002). As an extension of phase I, MICS-Asia phase II included more chemical species of concern, such as sulfur, nitrogen, and ozone. This broader collaborative study examined four different periods, encompassing two different years and three different seasons (March, July, and December in 2001, and March in 2002). Simulation results from nine different regional modeling groups were analyzed. Detailed information about this project can be found in the overview paper of Carmichael et al. (2008). In 2010, the MICS-Asia III project was launched. As a part of the Acid Deposition Monitoring Network in East Asia (EANET), additional research activity, and a continuing research of MICS-Asia series, three topics were discussed, including comparison and evaluation of current multi-scale air quality models (topic 1), development of reliable emission inventories for CTMs in Asia (topic 2 ), and interactions between air quality and climate changes (topic 3).

This paper focuses on the first topic of the MICS-Asia phase III and intends to present and summarize the following three objectives, specializing in the topic of aerosols. Firstly, comprehensive evaluations of the strengths and weaknesses of current CTMs for simulating particulate matter (PM) are provided against extensive in situ and satellite measurements, aiming to show the capability of participant models. Secondly, diversities of simulated aerosol concentrations among participant models are analyzed, including possible reasons for the inconsistency. Thirdly, characteristics of aerosol compositions in six metropolitan cities in East Asia are analyzed, which may be helpful to take measures to prevent and control air pollution in the future.

The description of model configurations, model inputs, and observations are presented in Sect. 2. The evaluation of model performance and the intercomparison between participant models are shown in Sect. 3. The conclusions and discussions are presented in Sect. 4.

\section{Intercomparison framework}

A total of 14 regional models (M1-M14) participated in MICS-Asia phase III topic 1. All models were required to run for all of the year 2010, and provide gridded monthly simulation results of aerosols in the first model layer. These CTMs include the Weather Research and Forecasting model coupled with Community Multi-scale Air Quality (WRFCMAQ), WRF-Chem, the nested air quality prediction model system (NAQPMS), the non-hydrostatic mesoscale model coupled with chemistry transport model (NHM-Chem), the Goddard Earth Observing System with chemistry (GEOSChem), and the Regional Atmospheric Modeling System coupled with CMAQ (RAMS-CMAQ). Among these models, there are three different versions of WRF-CMAQ (v5.0.2 is used by M1 and M2, v5.0.1 is used by M3, and v4.7.1 is used by M4, M5, and M6), four different versions of WRFChem (v3.7.1 is used by M7, v3.6.1 is used by M8, v3.6 is used by M9, and v3.5.1 is used by M10), one version of NAQPMS (M11), NHM-Chem (M12), GEOS-Chem (v9.1.3 is used by M13), and RAMS-CMAQ (v4.6 is used by M14). Basic information about the configurations of each model is summarized in Table 1.

\subsection{Model configurations}

\subsubsection{Simulation domain}

A unified simulation domain was designed by MICS-Asia organizers, which covers the region of $\left(15.4^{\circ} \mathrm{S}-58.3^{\circ} \mathrm{N}, 48.5-\right.$ $160.2^{\circ} \mathrm{E}$ ) with $180 \times 170$ grid points at $45 \mathrm{~km}$ horizontal resolution, but participant models employed different modeling domains (Fig. 1) with different grid resolutions (e.g., $0.5^{\circ}$ latitude $\times 0.667^{\circ}$ longitude in M13, $64 \mathrm{~km} \times 64 \mathrm{~km}$ in M14, and $45 \mathrm{~km} \times 45 \mathrm{~km}$ in the others). In order to minimize the influence from lateral boundary conditions and to cover most areas of interest in East Asia, an analyzed region was chosen in this paper (Fig. 1). For M13 and M14, missing values were used to fill the grids outside their simulation domains. Meanwhile, the analyzed region was divided into five different areas (Region_1 to Region_5). Region_1 contains the Korean Peninsula and Japan. Region_2 only contains China. Region_3 contains Mongolia and parts of Russia. Region_4 covers most countries in southeast Asia. Region_5 contains most countries in South Asia. Therefore, simulation results in each subregion can be analyzed and compared to show the performance of current CTMs.

\subsubsection{Gas and aerosol modules}

Gas-phase chemistry and aerosol chemistry are important parameterizations in CTMs. Luecken et al. (2008) and Balzarini et al. (2014) pointed out that different settings of chemical mechanisms could influence the simulation results significantly. 


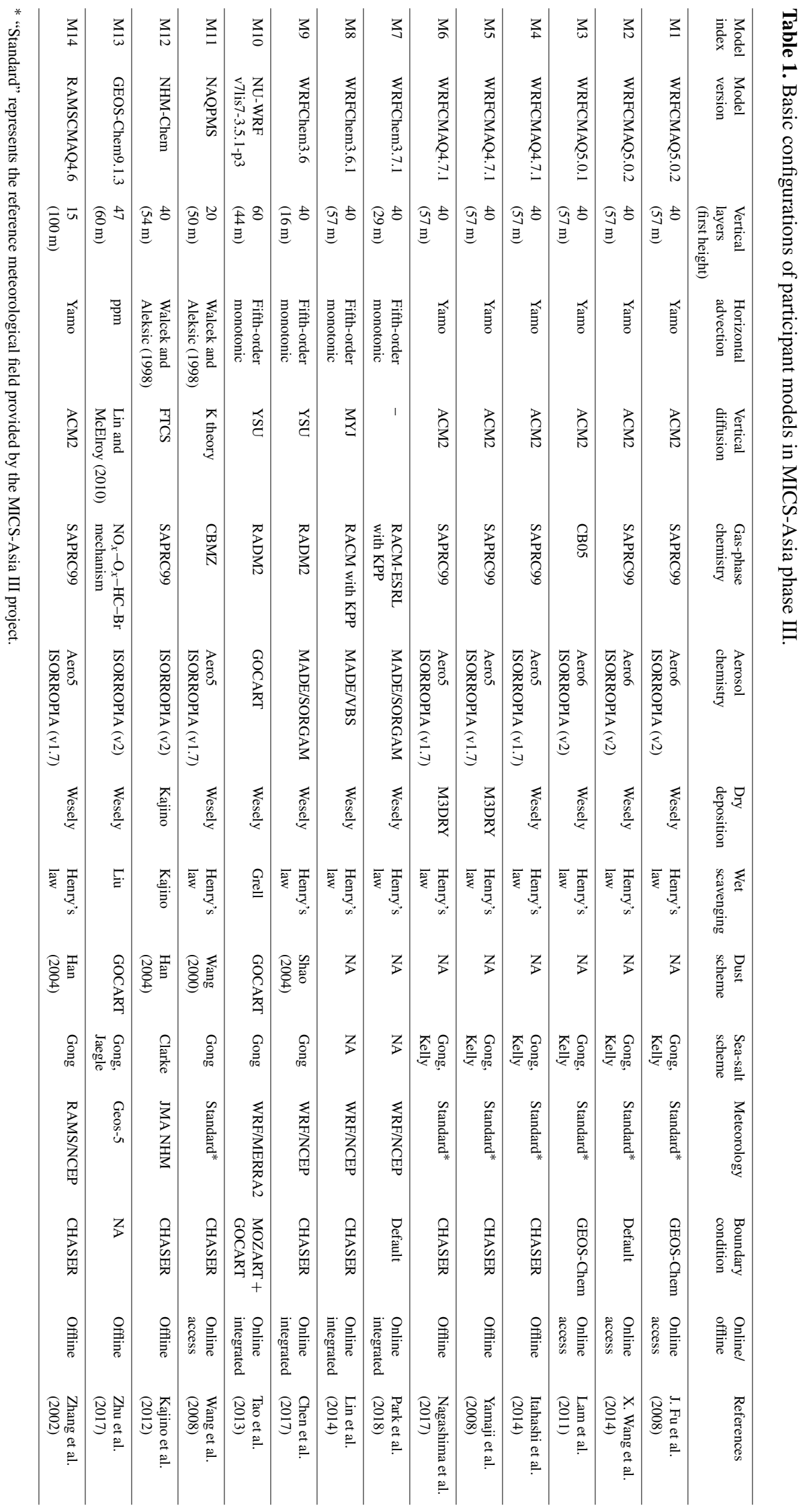




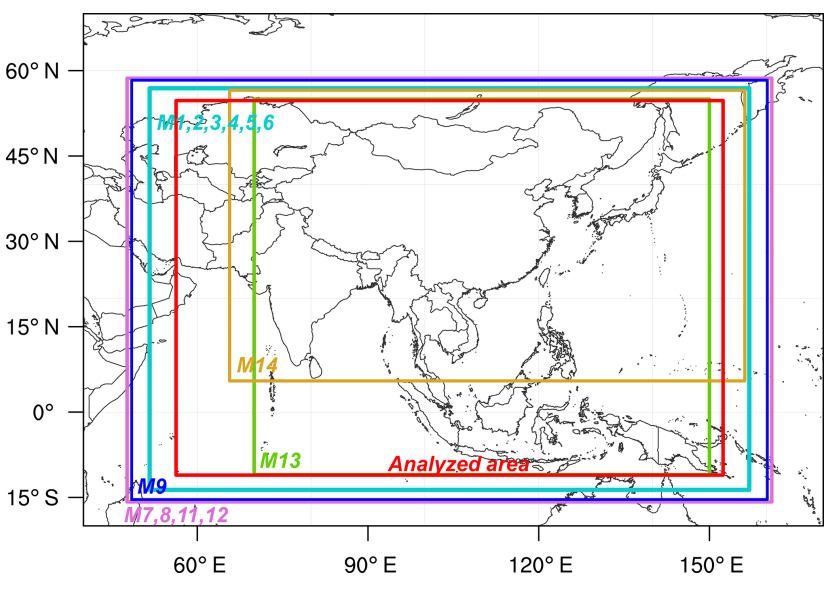

Figure 1. Simulation domain for each participant model. The final analyzed region is also shown.

\section{Gas-phase chemistry}

1. The gas chemistry of SAPRC99 (Statewide Air Pollution Research Center 99) was used in M1, M2, M4, M5, M6, M12, and M14. It is a detailed mechanism for the gas-phase atmospheric reactions of VOCs and $\mathrm{NO}_{x}$ in urban and regional atmosphere (Carter, 2000). The SAPRC99 mechanism has already been incorporated into CMAQ v4.6 with about 72 species and 214 reactions. Meanwhile, another three heterogeneous chemistry reactions of $\mathrm{N}_{2} \mathrm{O}_{5}, \mathrm{HO}_{2}$, and $\mathrm{NO}_{2}$ are also considered in the SAPRC99 gas-phase chemistry in M12 (Kajino et al., 2018).

2. The Carbon Bond mechanism (CB05) was used in M3. It describes tropospheric oxidant chemistry and provides a basis for computer modeling studies of ozone, particulate matter, visibility, acid deposition, and air toxicity issues, with 51 species and 156 reactions (Yarwood et al., 2005).

3. The second-generation Regional Acid Deposition Model (RADM2) gas-phase chemical mechanism was used in M9 and M10. The inorganic species considered in RADM2 include 14 stable species, four reactive intermediates, and three abundant stable species. The organic chemistry is represented by 26 stable species and 16 peroxy radicals (Stockwell et al., 1990). This module can simulate the concentrations of PAN, $\mathrm{HNO}_{3}$, and $\mathrm{H}_{2} \mathrm{O}_{2}$ under different environmental conditions (Stockwell et al., 1990).

4. Based on RADM2, the Regional Atmospheric Chemistry Mechanism (RACM) was developed with updated reaction rate constants and product yields according to more recent laboratory measurements. It is capable of simulating the troposphere from the Earth's surface through the upper troposphere and is valid for simulating remote to polluted urban conditions (Stockwell et al., 1997). M7 and M8 selected the RACM module. The rate coefficients were further updated in $\mathrm{M} 7$ (Kim et al., 2009). However, heterogeneous hydrolysis of $\mathrm{N}_{2} \mathrm{O}_{5}$ is not considered in M7 and M8.

5. The gas chemistry of Carbon Bond mechanism version $\mathrm{Z}$ (CBMZ) was used in M11. This lumped-structure mechanism extends the original framework of CBMIV to function properly at larger spatial and longer timescales, with revised inorganic chemistry, isoprene chemistry, and many other related parameterizations (Zaveri and Peters, 1999).

6. In $\mathrm{M} 13$, the $\mathrm{NO}_{x}-\mathrm{O}_{x}-\mathrm{HC}-\mathrm{Br}$ tropospheric gas chemistry mechanism was used. It includes about 80 species and 300 chemical reactions (Bey et al., 2001; Zhu et al., 2017).

Jimenez et al. (2003), Luecken et al. (2008), and Yang et al. (2018) summarized that different gas-phase chemistry mechanisms could predict large variations in reactive species, such as $\mathrm{HO}_{2}$ and $\mathrm{NO}_{3}$, making the production of $\mathrm{OH}$ and $\mathrm{H}_{2} \mathrm{O}_{2}$ different. In addition to the different number of species and reactions considered in each gas module, the reaction rates of the oxidation of $\mathrm{SO}_{2}, \mathrm{NO}_{x}$, and some VOCs to condensable $\mathrm{SO}_{4}^{2-}, \mathrm{NO}_{3}^{-}$, and organic species are also largely different (Pan and Zhang, 2008). All these would affect the simulated aerosol concentrations, especially under the urban condition.

\section{Aerosol chemistry}

1. AERO with ISORROPIA: aerosol modules (AERO5 and AERO6) with thermodynamic equilibrium models (ISORROPIA v1.7 and v2) were used in M1, M2, M3, M4, M5, M6, M11, M12, and M14. Aerosols in AERO were divided into three modes: Aitken, accumulation, and coarse modes. Gas-liquid-solid equilibrium in inorganic aerosol was predicted by the ISORROPIA model. The AERO5 ISORROPIA (v1.7) was mainly used in CMAQ v4, and the updated AERO6 ISORROPIA (v2) has been implemented since CMAQ v5. Overall, nine new PM species (e.g., $\mathrm{Ca}^{2+}, \mathrm{K}^{+}$, and $\mathrm{Mg}^{2+}$ ) were added in the new aerosol module of AERO6. In order to support the additional crustal ion emissions introduced in AERO6, ISORROPIA (v1.7) was replaced by ISORROPIA (v2) (Nenes et al, 1998; Fountoukis and Nenes, 2007), and the corresponding modifications could affect the gas-particle partitioning of $\mathrm{NO}_{3}^{-}$and $\mathrm{NH}_{4}^{+}$. The rate constants for the $\mathrm{S}$ (IV) to $\mathrm{S}$ (VI) conversion through in-cloud oxidation pathways were also modified, including the catalysis effects through aqueous chemistry from $\mathrm{Fe}$ and $\mathrm{Mn}$ (Appel et al., 2013). In order to solve the overpredictions of 
the unspeciated $\mathrm{PM}_{2.5}$ (also called $\mathrm{PM}_{\mathrm{other}}$ ) in CMAQ $\mathrm{v} 4$, detailed speciation profiles derived from Reff et al. (2009) were adopted in CMAQ v5 to subdivide the emissions of $\mathrm{PM}_{\mathrm{other}}$ into primary $\mathrm{NO}_{4}^{+}, \mathrm{Na}^{+}, \mathrm{Cl}^{-}$, and other selected trace elements. Comparing with $\mathrm{CMAQ}$ v4.6, a new parameterization of heterogeneous $\mathrm{N}_{2} \mathrm{O}_{5}$ hydrolysis was included in CMAQ v4.7 to improve the simulation results of $\mathrm{NO}_{3}^{-}$. Comparing with CMAQ v5.0.1, a mass balance correction of $\mathrm{NO}_{3}^{-}$aerosol under cold conditions was adopted in CMAQ v5.0.2. This adjustment would reduce the concentration of $\mathrm{NO}_{3}$ and $\mathrm{HNO}_{3}$ at the surface level.

2. MADE/SORGAM and MADE/VBS: detailed treatments of inorganic aerosol effects in M7, M8, and M9 were simulated by Modal Aerosol Dynamics Model for Europe (MADE). Three log-normal modes (Aitken, accumulation, and coarse modes) were used in this module to present the particle size distribution of submicrometer aerosol, such as $\mathrm{SO}_{4}^{2-}, \mathrm{NO}_{3}^{-}, \mathrm{NH}_{4}^{+}$, black carbon (BC), OC, and aerosol water (Ackermann et al., 1998). Aerosols were assumed to be internally mixed in the same mode but externally mixed among different modes (Zhao et al., 2010). The organic chemistry used in M7 and M9 was based on SORGAM (Secondary Organic Aerosol Model). This model was capable of simulating SOA formation including the production of low-volatility products and their subsequent gasparticle partitioning (Schell et al., 2001), but all activity coefficients were assumed to be 1 due to insufficient information. However, when it was coupled with MADE, the biogenic precursors and their resulting particle concentrations were set to be zero. The organic chemistry used in M8 was based on the volatility basis set (VBS) approach (Ahmadov et al., 2012). This module used the volatility basis set framework to simulate primary organic aerosol partitioning between the gas and particulate phases and the gas-phase oxidation of the corresponding vapors (Murphy and Pandis, 2009).

3. GOCART: the Goddard Chemistry Aerosol Radiation and Transport (GOCART) model was used in M10 to simulate tropospheric aerosol components, such as $\mathrm{SO}_{4}^{2-}$, dust, $\mathrm{BC}, \mathrm{OC}$, and sea-salt aerosols $\left(\mathrm{NO}_{3}^{-}\right.$and $\mathrm{NH}_{4}^{+}$are not considered), and all these aerosol species were assumed to be log-normal size distributions (Chin et al., 2000). $\mathrm{SO}_{4}^{2-}$ was formed by the oxidation of $\mathrm{SO}_{2}$ in the atmosphere, but the impacts from in-cloud oxidation pathways were not included (Chin et al., 2002). The source emission of $\mathrm{BC}$ and $\mathrm{OC}$ was mainly from biomass burning. Dust emission was following Ginoux et al. (2001). Sea-salt emission was highly dependent on wind speed. More details about the simulations of dust and sea-salt aerosols in GOCART will be described in Sect. 2.1.3 and 2.1.4.
Different chemical species are considered in numerous aerosol equilibrium models, resulting in different equilibrium partitioning and water uptake during the simulation processes, which can affect the predicted aerosol concentrations (Fountoukis and Nenes, 2007). As Moya et al. (2002) and Wang et al. (2012) classified that the treatment of crustal material in aerosol chemistry could considerably improve model results in predicting the partitioning of $\mathrm{NO}_{3}^{-}$and $\mathrm{NH}_{4}^{+}$. Different heterogeneous reactions and their activity coefficients used in the thermodynamic equilibrium would also be a major source of uncertainty in simulated aerosol concentrations (Li et al., 2012; Kim et al., 2011; D. Chen et al., 2016).

\subsubsection{Dust scheme}

Natural emissions of windblown dust have been explicitly parameterized since CMAQ v5 (Foroutan et al., 2017), but all the participating WRF-CMAQ models did not turn this option on, which means dust aerosols were not considered in M1-M6. Meanwhile, the dust scheme in M7 and M8 was also turned off.

Dust particles in M10 and M13 were simulated by the GOCART model (Ginoux et al., 2001). This model includes eight size groups of mineral dust ranging from 0.1 to $10 \mu \mathrm{m}$. The emission flux for a size group can be expressed as follows: $F=C \times S \times s_{p} \times u_{10}^{2} \times\left(u_{10}-u_{\mathrm{t}}\right)$, if $u_{10}>u_{\mathrm{t}}$, where $C$ is a constant with the value of $1 \mu \mathrm{g} \mathrm{s}^{2} \mathrm{~m}^{-5} . S$ means the probability source function, representing the fraction of alluvium available for wind erosion. $s_{p}$ is the fraction of each size group within the soil. $u_{10}$ and $u_{\mathrm{t}}$ are the wind speed at $10 \mathrm{~m}$ and threshold velocity of wind erosion, respectively.

A simplified dust emission parameterization proposed by Shao (2001) was used in M9 (Shao, 2004). Dust emission in Shao (2004) is proportional to streamwise saltation flux, and the proportionality depends on soil texture and soil plastic pressure. The size-resolved dust flux goes into four size bins, with diameters ranging from 1.95 to $20 \mu \mathrm{m}$ (Kang et al., 2011). More details about the dust emission rate and the total dust flux can be found in Shao (2004).

A size-segregated dust deflation module proposed by Wang et al. (2000) was used in M11. It was developed based on three major predictors (friction velocity, surface humidity, and dominant weather system) and has been successfully applied in many dust-related simulations (Wang et al., 2002; Yue et al., 2010). The dust flux $F$ is calculated as follows: $F=C \times \frac{\rho_{\mathrm{a}}}{g} \times E \times u^{* 3} \times\left(1+\frac{u_{0}^{*}}{u^{*}}\right) \times\left(1-\frac{u_{0}^{* 2}}{u^{* 2}}\right) \times\left(1-\frac{\mathrm{RH}}{\mathrm{RH}_{0}}\right)$, where $C$ is equal to $10^{-5}, \rho_{\mathrm{a}}$ indicates air density, and $g$ is gravitational acceleration. $E$ is the weighting factor, representing the uplifting capability of land surface. $u_{0}^{*}$ and $u^{*}$ are the fraction and threshold friction velocities, respectively. $\mathrm{RH}$ and $\mathrm{RH}_{0}$ are relative humidity and threshold relative humidity, respectively. According to soil categories and vegetation coverage, the dust emission intensity was further modified by Luo and Wang (2006). Four size bins of dust particles 
ranging from 0.43 to $10 \mu \mathrm{m}$ were considered in this emission module. Meanwhile, several heterogeneous reactions on dust particles were also considered (J. Li et al., 2012).

An empirical dust emission mechanism based on the approach of Gillette and Passi (1988) was used in M12 and M14 (Han et al., 2004). Dust flux can be calculated through the following formula: $F=C \times u_{*}^{4} \times\left(1-\frac{u_{*}}{u}\right) \times(1-f \times R)$, if $u>u_{*}$, where $u$ and $u_{*}$ are the friction and the threshold friction velocities, respectively. $C$ is the correction coefficient $\left(1.4 \times 10^{-15}\right) . f$ and $R$ represent the fractional coverage of vegetation and the reduction factor in a model grid. Dust particles with diameters ranging from 0.43 to $42 \mu \mathrm{m}$ were grouped into 11 bins, with the first eight bins below $11 \mu \mathrm{m}$ for aerosol sampler, and the additional three bins above $11 \mu \mathrm{m}$ for larger particles (Han et al., 2004).

Different dust schemes will produce different dust emission fluxes over arid and semi-arid regions (Zhao et al., 2010; Su and Fung, 2015). Several factors, such as potential source regions, threshold friction velocity, size distribution, and other surface and soil-related parameters used in equations, can be the primary causes for the inconsistency, and the differences in simulated dust emissions will affect the characteristics of spatial-temporal variations of atmospheric aerosol particles.

\subsubsection{Sea-salt scheme}

As one of the major components of primary aerosols, sea-salt aerosols contributes to $20 \%-40 \%$ of secondary inorganic aerosols (SIAs) over coastal regions (Liu et al., 2015; Yang et al., 2016). These particles can provide surface areas for condensation and reaction of nitrogen and sulfur, making the simulated concentrations of SIAs more accurate (Kelly et al., 2010; Im, 2013).

In M12, the method of Clarke et al. (2006) was used to simulate the sea-salt emissions as follows: $S_{100}=$ $\frac{C_{s} \times k \times V_{\text {wind }} \times h}{A_{\text {avg }} \times L+0.5 \times w_{0}}$. The sea-salt source function $\left(S_{100}\right)$ is defined as the number of sea-salt aerosols generated per unit area of ocean surface completely covered by bubbles $(100 \%$ coverage) per unit time. $C_{s}$ is the differences of condensation nuclei concentrations collected at $5 \mathrm{~m}$ (impacted by breaking waves) and $20 \mathrm{~m}$ (background values). $k$ is the multiplier for tower $C_{s}$ compared to the mean profile. $V_{\text {wind }}$ indicates surf zone wind speed. $h$ is the height of plume layer for beach profile. $A_{\text {avg }}$ represents mean bubble fractional coverage area between waves. $L$ is the distance wave travels to shore, and $w_{0}$ is the initial width of breaking-wave bubble front.

In other participating models (sea-salt emission is not considered in M7 and M8), sea-salt emissions were simulated online by using the algorithm proposed by Gong et al. (2003). The density function $\frac{\mathrm{d} F}{\mathrm{~d} r}\left(\mathrm{~m}^{-2} \mathrm{~s}^{-2} \mu \mathrm{m}^{-1}\right)$ is calculated as follows: $\frac{\mathrm{d} F}{\mathrm{~d} r}=1.373 \times u_{10 \mathrm{~m}}^{3.41} \times r^{-A} \times\left(1+0.057 \times r^{3.45}\right) \times$ $10^{1.607 e^{-B^{2}}}$, where $u_{10 \mathrm{~m}}$ is the $10 \mathrm{~m}$ wind speed, and $r$ is the particle radius at $\mathrm{RH}$ of $80 \%$. A represents an adjustment parameter, which control the shape of submicron size distribution. $B=\left(0.433-\log _{10}(r)\right) / 0.433$, meaning a parameter related to particle radius. In CMAQ model, the sea-salt scheme was updated by Kelly et al. (2010) to enhance the emission of sea salt from the coastal surf zone and to allow dynamic transfer of $\mathrm{HNO}_{3}, \mathrm{H}_{2} \mathrm{SO}_{4}, \mathrm{HCl}$, and $\mathrm{NH}_{3}$ between coarse particles and gas phase. In GEOS-Chem, it was updated by Jaegle et al. (2011) to improve the simulation of sea salt with dry radii smaller than $0.1 \mu \mathrm{m}$.

\subsection{Model inputs}

Based on the experience concluded from phase I and phase II, all 14 models in phase III topic 1, in principle, were required to use the "standard" meteorological fields, emission inventories, and boundary conditions in order to reduce the potential diversities caused by model inputs. But different data were selected by participant models. In this section, some basic information about the model inputs are described.

\subsubsection{Meteorological fields}

The "standard" hourly meteorological fields were simulated by WRF v3.4.1 with the initial and lateral boundary conditions taken from the National Centers for Environmental Prediction (NCEP) Final Analysis (FNL) data. Fourdimensional data assimilation nudging toward the NCEP FNL data was also adopted to increase the accuracy of simulated meteorological variables. The reference meteorological fields were only used in M1-M6 and M11. For M7, M8, and M9, the standard meteorological simulation was run by the same model (WRF), but feedbacks between meteorological variables and pollutants were also considered in these WRFChem models. For M10, the Modern-Era Retrospective analysis for Research and Applications (MERRA) reanalysis was used to drive the WRF (v3.5.1) model. The outputs from the Japan Meteorological Agency (JMA) NHM were used to initialize M12 (Kajino et al., 2012). M13 was driven by assimilated meteorological data from GEOS of NASA's Global Modeling and Assimilation Office (Chen et al., 2009; K. Li et al., 2016b). Although the meteorological initial and lateral boundary conditions were taken from the same NCEP FNL data, three-dimensional meteorological fields used in M14 were simulated by Regional Atmospheric Modeling System (RAMS) (Zhang et al., 2002, 2007; Han et al., 2009, 2013). Consequently, different meteorological fields used in the 14 participant models will cause different atmospheric circulation characteristics, which can further influence the spatialtemporal variation of air pollutants (Gao et al., 2018).

\subsubsection{Emission inventories}

All participant models utilized the "standard" emission inventory, including anthropogenic, biogenic, biomass burning, air and ship, and volcano emissions, which was prepared by the emission group in MICS-Asia phase III. The 
anthropogenic emission dataset over Asia, named MIX, was developed by harmonizing five regional and national emission inventories with a mosaic approach. These five inventories are REAS2 (REAS inventory version 2.1 for all of Asia; Kurokawa et al., 2013), MEIC (the Multi-resolution Emission Inventory for China developed by Tsinghua University), $\mathrm{PKU}-\mathrm{NH}_{3}$ (a high-resolution $\mathrm{NH}_{3}$ emission inventory by Peking University; Huang et al., 2012), ANL-India (an Indian emission inventory developed by Argonne National Laboratory; Lu et al., 2011), and CAPSS (the official Korean emission inventory form the Clean Air Policy Support System; Lee et al., 2011). The MIX inventory includes 10 species $\left(\mathrm{SO}_{2}, \mathrm{NO}_{x}, \mathrm{CO}, \mathrm{CO}_{2}, \mathrm{NMVOCs}\right.$ (nonmethane volatile organic compounds), $\mathrm{NH}_{3}$ (ammonia), $\mathrm{BC}$ (black carbon), OC (organic carbon), $\mathrm{PM}_{2.5}$, and $\mathrm{PM}_{10}$ ) in each sector (power, industry, residential, transportation, and agriculture) and is developed for the year 2010 with monthly temporal resolution and $0.25^{\circ}$ spatial resolution. More details can be found in M. Li et al. (2017). Weekly and diurnal profiles of the anthropogenic emissions provided by the emission group were used in model simulations, including the emission factors for the first seven vertical levels (Fig. S1 in the Supplement). Biogenic emissions were calculated by the Model of Emissions of Gases and Aerosols from Nature (MEGAN) version 2.04 (Guenther et al., 2006). In MEGAN v2.04, meteorological variables (e.g., solar radiation, air temperature, soil moisture) and land cover information (e.g., leaf area index and plant functional types) were necessary inputs, and these data were obtained from the WRF v3.4.1 simulation results and MODIS (Moderate Resolution Imaging Spectroradiometer) products, respectively. Biomass burning emissions were processed by regridding Global Fire Emissions Database (GFED) version 3 (van der Werf et al., 2010), and the diurnal profile was also provided. The aircraft and shipping emissions were based on the 2010 HTAPv2 (Hemispheric Transport of Air Pollution) emission inventory $\left(0.1^{\circ}\right.$ by $\left.0.1^{\circ}\right)$ (Janssens-Maenhout et al., 2015). Daily volcanic $\mathrm{SO}_{2}$ emissions were collected from the AEROCOM program (https://aerocom.met.no/ DATA/download/emissions/AEROCOM_HC/volc, last access: 11 September 2019, Diehl et al., 2012; Stuefer et al., 2013). The spatial distributions of the merged emissions of $\mathrm{SO}_{2}, \mathrm{NO}_{x}, \mathrm{NH}_{3}$, and $\mathrm{PM}_{2.5}$ from anthropogenic, biogenic, biomass burning, air and ship, and volcano emissions are shown in Fig. S2. Similar spatial patterns can be found among the four species, with high values in eastern China and northern India.

\subsubsection{Boundary conditions}

Two sets of the chemical initial and boundary conditions (CHASER and GEOS-Chem) were provided by MICS-Asia phase III. The 3-hourly global CTM outputs of CHASER (prepared by Nagoya University; Sudo et al., 2002a, b) were run with $2.8^{\circ} \times 2.8^{\circ}$ horizontal resolution and 32 vertical lay- ers. The hourly outputs from GEOS-Chem (prepared by University of Tennessee; http://acmg.seas.harvard.edu/geos/, last access: 11 September 2019 ) was run with $2.5^{\circ} \times 2^{\circ}$ horizontal resolution and 47 vertical layers. All participant models, except M2, M7, and M10, chose between them. For M2 and M7, the default chemical boundary conditions provided by CMAQ and WRF-Chem were used, respectively. For M10, the global GOCART simulations were used for atmospheric aerosols.

\subsection{Coupled meteorology and chemistry modeling methods}

As is known to all that meteorological fields have significant influences on air quality. Meanwhile, atmospheric compositions can also affect weather and climate. As Gao et al. (2018) pointed out, different coupling methods between aerosols and meteorological variables can cause different simulation results.

In order to simulate the concentrations of air pollutants, meteorological models and chemistry transport models should be implemented either offline or online (Kong et al., 2015). Offline modeling implies that the CTM is run after the meteorological simulation is completed, which means the chemical impacts on meteorology are not considered. Online modeling allows coupling and integration of some of the physical and chemical components (Baklanov et al., 2014). According to the extent of online coupling, there are two ways of coupling: (1) online integrated coupling (meteorology and chemistry are simulated simultaneously in the same grid) and (2) online access coupling (meteorology and chemistry are independent, but information can be exchanged between meteorology and chemistry) (Baklanov et al., 2014). Among these participating models, M4, M5, M6, M12, M13, and M14 are offline models. M1, M2, M3, and M11 are online access models. M7, M8, M9, and M10 are online integrated models.

More details about the model configurations can be found in Table 1 and the other MICS-Asia phase III companion papers (Kong et al., 2019; Li et al., 2019).

\subsection{Observation data}

Monthly observations of $\mathrm{SO}_{4}^{2-}, \mathrm{NO}_{3}^{-}, \mathrm{NH}_{4}^{+}, \mathrm{PM}_{2.5}$, and $\mathrm{PM}_{10}$ collected from 39 stations of EANET were used to evaluate the simulations. Common quality-assurance and quality-control standards promoted by the ADORC (Acid Deposition and Oxidant Research Center) were adopted among these EANET stations to guarantee a high-quality dataset. More information about the EANET dataset can be found at http://www.eanet.asia/index.html (last access: 11 September 2019). In addition to the EANET data, monthly mean concentrations of air pollutants (e.g., $\mathrm{SO}_{2}$, $\mathrm{NO}_{2}, \mathrm{PM}_{2.5}$, and $\mathrm{PM}_{10}$ ) over the Beijing-Tianjin-Hebei (BTH) region (19 sites) and the Pearl River Delta (PRD) re- 


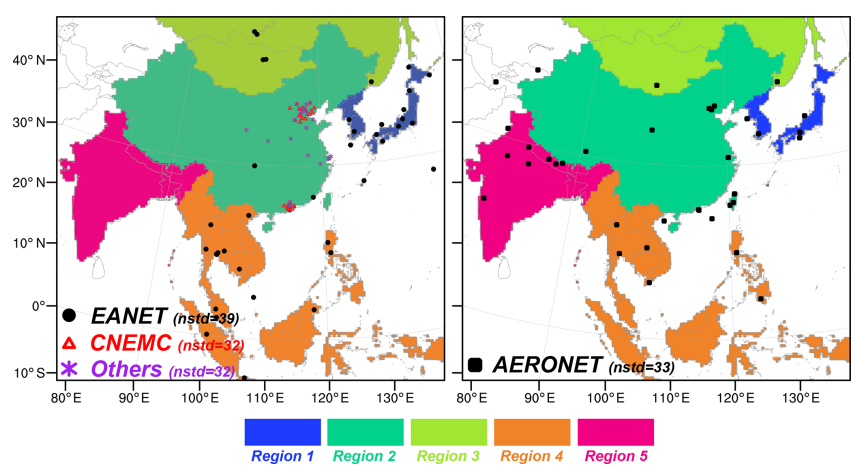

Figure 2. The geographical locations of observation stations: EANET (shown in black circles; the number of stations is 39), CNEMC (shown in red triangles; the number of stations is 32), others (observations collected from published literature, shown in purple stars; the number of stations is 32), and AERONET (shown in black boxes; the number of stations is 33 ). Five defined subregions (Region_1 to Region_5) are also shown.

gion (13 sites) provided by the China National Environmental Monitoring Center (CNEMC) were also used to compare with the simulation results from participating models.

As is known to all, China has been experiencing heavy air pollution with high concentrations of fine particles. Recent studies highlighted the importance of secondary aerosols in the formation of haze episodes (Liu et al., 2013; Sun et al., 2016a; Chen et al., 2018). However, observations (e.g., $\mathrm{SO}_{4}^{2-}, \mathrm{NO}_{3}^{-}$and $\mathrm{NH}_{4}^{+}$) in China were only available at one EANET site (the Hongwen site). In order to make the model evaluation more credible, observed monthly/seasonal/yearly concentrations of $\mathrm{BC}, \mathrm{SO}_{4}^{2-}, \mathrm{NO}_{3}^{-}, \mathrm{NH}_{4}^{+}$, and $\mathrm{PM}_{2.5}$ in China were also collected from published literature.

The Aerosol Robotic Network (AERONET), a groundbased remote-sensing aerosol network consisting of worldwide automatic Sun- and sky-scanning spectral radiometers (Holben et al., 1998), provides the aerosol optical depth (AOD) products at 440 and $675 \mathrm{~nm}$, which can be used to calculate the AOD at $550 \mathrm{~nm}$ according to the Ångström exponent. The AERONET level 2.0 monthly AOD (cloudscreened and quality-assured) data at 33 sites were utilized in this study. Meanwhile, satellite-retrieved $550 \mathrm{~nm}$ AOD products from the Moderate Resolution Imaging Spectroradiometer (MODIS) were also used to compare with simulations.

Figures 2 and $\mathrm{S} 3$ show the geographical locations of all the observation sites. Most $\mathrm{SO}_{4}^{2-}, \mathrm{NO}_{3}^{-}$, and $\mathrm{NH}_{4}^{+}$monitoring sites are located in China, Japan, and southeast Asia. Three $\mathrm{PM}_{10}$ sites are located in southeast Asia, while others are in China and Japan. Detailed information about these stations is listed in Tables S1 and S2.

In general, the wide variety of in situ and satellite measurements used in this paper can allow for a rigorous and comprehensive evaluation of model performance.

\section{Results}

\subsection{Model evaluation}

According to the objective of MICS-Asia phase III topic 1, comparisons of aerosol concentrations between observations and simulations are presented to evaluate the performance of current multi-scale air quality models in East Asia, including analyzing the similarities and differences between participant models. Simulation results of $\mathrm{BC}, \mathrm{OC}, \mathrm{SO}_{4}^{2-}, \mathrm{NO}_{3}^{-}$, $\mathrm{NH}_{4}^{+}, \mathrm{PM}_{2.5}, \mathrm{PM}_{10}$, and $\mathrm{AOD}$ are requested to submit for the project, but no data can be acquired from M10, and extremely large values are predicted by M3. Therefore, only 12 models are actually considered in this paper. Among the 12 models, AOD is missing in M5, M6, and M8, $\mathrm{PM}_{10}$ is missing in $\mathrm{M} 13$, OC is missing in $\mathrm{M} 7$, and $\mathrm{BC}$ and $\mathrm{OC}$ are missing in M9 (Table S3).

\subsubsection{Evaluation for aerosol compositions}

Figure 3 illustrates the observed and simulated groundlevel annual mean concentrations of $\mathrm{BC}, \mathrm{SO}_{4}^{2-}, \mathrm{NO}_{3}^{-}, \mathrm{NH}_{4}^{+}$, $\mathrm{PM}_{2.5}$, and $\mathrm{PM}_{10}$. Multi-model ensemble mean (MMEM), defined as the average of all available participating models (except M3 and M10), is presented to exhibit a composite of model performance. Normalized mean biases (NMBs) between observations and MMEM in each defined subregion (Region_1 to Region_5) and the whole analyzed region (Region_All) are also calculated.

Analyzing Fig. 3a, we can find that most models show good skills in simulating the $\mathrm{BC}$ concentrations and their spatial distribution characteristics, with relative high values over large emission areas (e.g., north China) (K. Li et al., 2016a). But the NMB for MMEM is $-15.8 \%$. This underestimation may be attributed to the large negative bias at the Gucheng site (site 24) (NMB for MMEM is $-38.3 \%$ ). This station is located in the industrial province of Hebei, where air pollution is serious and $\mathrm{BC}$ emission is large (P. Wang et al., 2016). Due to the low reactivity of $B C$ in the atmosphere, the high uncertainty of $\mathrm{BC}$ in current emission inputs (Hong et al., 2017; M. Li et al., 2017) may cause this underestimation.

For $\mathrm{SO}_{4}^{2-}$, observations are relative low in Region_1 (mean value is $3.8 \mu \mathrm{g} \mathrm{m}^{-3}$ ), Region_3 (mean value is $2.5 \mu \mathrm{g} \mathrm{m}^{-3}$ ), and Region_4 (mean value is $3.5 \mu \mathrm{g} \mathrm{m}^{-3}$ ), and most models (except M7, M9, and M14) perform well over these areas (NMBs range from $-26.3 \%$ to $30.0 \%$ ). In Region_2, all the observed concentrations of $\mathrm{SO}_{4}^{2-}$ are larger than $10 \mu \mathrm{g} \mathrm{m}^{-3}$ (mean value is $16.9 \mu \mathrm{g} \mathrm{m}^{-3}$ ), but models fail to reproduce the high magnitude. As Zheng et al. (2015) and Shao et al. (2019) pointed out, missing sulfate formation mechanisms (e.g., heterogeneous sulfate chemistry) on aerosol in current air quality models may result in this underestimation, especially in China where significant increase of secondary aerosols (such as sulfate) can be observed during polluted periods (Liu et al., 2015). A large 

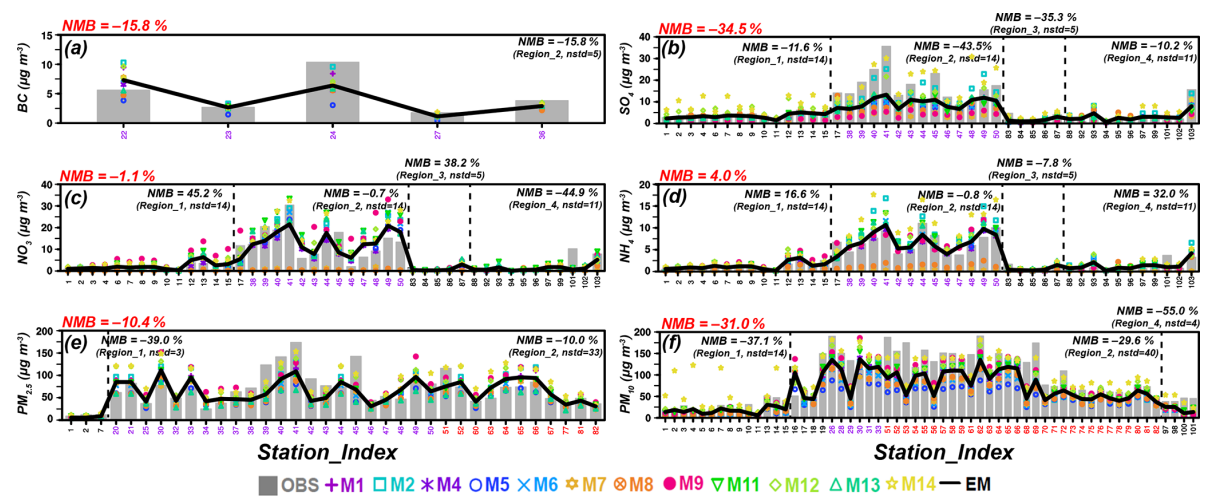

Figure 3. Comparison of observed and simulated concentrations of (a) $\mathrm{BC}$, (b) $\mathrm{SO}_{4}^{2-}$, (c) $\mathrm{NO}_{3}^{-}$, (d) $\mathrm{NH}_{4}^{+}$, (e) $\mathrm{PM}_{2.5}$, and (f) $\mathrm{PM}_{10}$. In each panel, the grey bars represent observations, the colored dots represent simulations, and the solid black lines represent the MMEM (multimodel ensemble mean). The $x$ axis presents the monitoring sites (the information of these sites is listed in Table S1 in the Supplement). Normalized mean biases (NMBs) between observations and MMEM in each defined subregion (shown in black) and the entire analyzed region (shown in red) are also shown. In this figure, the annual mean observations are taken from EANET, CNEMC, and published literature.

variance is also simulated among models; e.g., M14 overpredicts the ground-level $\mathrm{SO}_{4}^{2-}$ concentrations, especially in Region_1 (NMB $=118.6 \%)$. This significant overestimation in coastal stations may be caused by its high concentrations of sea-salt aerosols (Fig. 10), which makes the sea-salt sulfate higher. Meanwhile, M7 and M9 obviously underpredict $\mathrm{SO}_{4}^{2-}$ at nearly all sites $(\mathrm{NMB}=-73.5 \%$ and $-71.7 \%$, respectively). Generally, MMEM can well reproduce the spatial variation of $\mathrm{SO}_{4}^{2-}$, but the predicted concentration is underestimated, especially in Region_2 $(\mathrm{NMB}=-43.5 \%)$ and Region_3 (NMB $=-35.3 \%)$.

For $\mathrm{NO}_{3}^{-}$, low concentrations are observed in Region_1 $\left(1.5 \mu \mathrm{g} \mathrm{m}^{-3}\right)$, Region_3 $\left(0.6 \mu \mathrm{g} \mathrm{m}^{-3}\right)$, and Region_4 $\left(1.8 \mu \mathrm{g} \mathrm{m}^{-3}\right)$, but high values are presented in Region_2 $\left(13.4 \mu \mathrm{g} \mathrm{m}^{-3}\right)$, showing the similar spatial distribution characteristics as the observed $\mathrm{SO}_{4}^{2-}$. In CTMs, there are two pathways about the nitrate formation. The dominant pathway is the homogeneous gas-phase reaction between $\mathrm{HNO}_{3}$ $\left(\mathrm{NO}_{2}\right.$ oxidation by $\mathrm{OH}$ during the daytime) and $\mathrm{NH}_{3}$ under ammonia-rich conditions, and the second pathway is the heterogeneous hydrolysis of $\mathrm{N}_{2} \mathrm{O}_{5}$ on aerosol surface at night in ammonia-poor environments (Seinfeld and Pandis, 2006; Archer-Nicholls et al., 2014). As $\mathrm{NH}_{4} \mathrm{NO}_{3}$ is semi-volatile species, and the equilibrium surface concentration of $\mathrm{H}_{2} \mathrm{SO}_{4}$ is set to be zero in CTMs, so $\left(\mathrm{NH}_{4}\right)_{2} \mathrm{SO}_{4}$ is the preferential species in the completion when $\mathrm{H}_{2} \mathrm{SO}_{4}$ and $\mathrm{HNO}_{3}$ are both present. Only if $\mathrm{NH}_{3}$ is in excess will $\mathrm{NH}_{4} \mathrm{NO}_{3}$ be formed. Analyzing the performance of each participant model, $\mathrm{NO}_{3}^{-}$concentration is overpredicted by most models, and the underestimation of $\mathrm{SO}_{4}^{2-}$ can be used to explain this overestimation (Chen et al., 2017). Meanwhile, the biases from model-calculated gas-phase oxidation (e.g., $\mathrm{NO}_{2}+\mathrm{OH} \rightarrow \mathrm{HNO}_{3}$ ) and/or gas-aerosol phase partitioning (e.g., $\mathrm{HNO}_{3(g)}+\mathrm{NH}_{3(g)} \leftrightarrow \mathrm{NH}_{4} \mathrm{NO}_{3(s, \text { aq })}$ ) may also result in the overestimation (Brunner et al., 2015; Gao et al., 2014).
However, M7 and M8 significantly underestimate the observed $\mathrm{NO}_{3}^{-}$concentrations ( $\mathrm{NMB} \sim-93.4 \%$ ). One reason for the extremely low values may result from the incorrect concentrations of $\mathrm{NH}_{3}$ simulated by $\mathrm{M} 7$ and M8 (Fig. S4). As Chen et al. (2016) pointed out, the amount of $\mathrm{NH}_{3}$ in the atmosphere is a key factor in determining the $\mathrm{NO}_{3}^{-}$concentration. Another reason for this underestimation is that M7 and M8 did not consider the impacts of $\mathrm{N}_{2} \mathrm{O}_{5}$ heterogeneous reaction $\left(\mathrm{N}_{2} \mathrm{O}_{5(g)}+\mathrm{H}_{2} \mathrm{O}_{(\mathrm{aq})} \rightarrow 2 \mathrm{HNO}_{3(\mathrm{aq})}\right)$. Su et al. (2017) pointed out that the hydrolysis of $\mathrm{N}_{2} \mathrm{O}_{5}$ can lead up to a $21.0 \%$ enhancement of $\mathrm{NO}_{3}^{-}$, especially over polluted regions. Although the NMB calculated in Region_All for MMEM is only $-1.1 \%$, MMEM systematically overpredicts observations in Region_1 $(\mathrm{NMB}=45.2 \%)$ and Region_3 $(\mathrm{NMB}=38.2 \%)$ but underpredicts them in Region_2 $(\mathrm{NMB}=-0.7 \%)$ and Region_4 $(\mathrm{NMB}=-44.9 \%)$.

Simulated $\mathrm{NH}_{4}^{+}$concentrations are influenced by the partitioning between gaseous $\mathrm{NH}_{3}$ and aerosol $\mathrm{NH}_{4}^{+}$, and are also associated with the $\mathrm{SO}_{4}^{2-}$ and $\mathrm{NO}_{3}^{-}$concentrations (Gao et al., 2018). Model predictions (except M7, M8, and M14) can reproduce the measurements relatively well in each defined subregion. But significant overestimation is shown by M14, while significant underestimation is simulated by M7 and M8, especially in Region_2 with NMBs of $72.2 \%$ for $\mathrm{M} 14,-94.9 \%$ for $\mathrm{M} 7$, and $-81.0 \%$ for M8, respectively. For M14, overestimated $\mathrm{SO}_{4}^{2-}$ and $\mathrm{NO}_{3}^{-}$make the concentrations of $\mathrm{NH}_{4}^{+}$higher, since more ammonium is required to neutralize particle-phase acid. For M7 and M8, extremely low concentrations of $\mathrm{NH}_{3}$ are simulated, which means less gaseous $\mathrm{NH}_{3}$ can be converted to aerosol $\mathrm{NH}_{4}^{+}$. In general, the calculated NMB in Region_All by MMEM is $4.0 \%$.

On average, the observed $\mathrm{PM}_{2.5}$ concentration in Region_2 is larger than $50 \mu \mathrm{g} \mathrm{m}^{-3}$, but the mean value in Region_1 is only about $10 \mu \mathrm{g} \mathrm{m}^{-3}$. All participating models can generally capture this spatial distribution pattern. However, 
significant underestimation is simulated at the three remote stations (sites 1, 2, and 7) in Region_1 with the NMB of $-39.0 \%$ for MMEM. Similar negative bias can also be found in Ikeda et al. (2013), who compared CMAQ (v4.7.1) simulation results against observations from the same remote monitoring stations (Rishiri and Oki) in 2010. Ikeda et al. (2013) pointed out that the underestimated concentrations of organic aerosols may cause this bias. In Region_2, the NMB for MMEM is $-10.0 \%$.

For $\mathrm{PM}_{10}$, the mean observed concentrations in each region are $26.6 \mu \mathrm{g} \mathrm{m}^{-3}$ (Region_1), $114.4 \mu \mathrm{g} \mathrm{m}^{-3}$ (Region_2), and $38.1 \mu \mathrm{g} \mathrm{m}^{-3}$ (Region_4), respectively. But nearly all participant models (except M14) underestimate the $\mathrm{PM}_{10}$ concentrations. M14 predicts higher concentrations in Region_1, especially at coastal sites, such as site 1 (Rishiri), site 2 (Ochiishi), site 4 (Sadoseki), site 7 (Oki), and site 14 (Cheju). The high-value anomalies in M14 at coastal stations can also be found in Fig. 10, and the positive bias may be caused by the emission and gravitational settling of sea salt. As Monahan and Muircheartaigh (1980) pointed out, sea-salt emissions can be enhanced in the surf zone due to the increased number of wave breaking events, and the degree of the enhancement highly depends on the $10 \mathrm{~m}$ wind speed used in the whitecap coverage parameterization. According to the simulation results from published literature, higher wind speed is simulated by M14 (RAMSCMAQ) when compared with observations, especially at coastal stations (Han et al., 2013, 2018). Meanwhile, a gravitational settling mechanism of coarse aerosols from upper to lower layers was added in $\mathrm{M} 14$, and the net effect of this update could make an increase in the concentrations of coarse particles, especially near coastal areas impacted by sea spray (Nolte et al., 2008). Generally, the NMB for MMEM in Region_All is $-31.0 \%$.

Time series of the monthly observed and simulated aerosol compositions, including $\mathrm{BC}, \mathrm{SO}_{4}^{2-}, \mathrm{NO}_{3}^{-}, \mathrm{NH}_{4}^{+}, \mathrm{PM}_{2.5}$, and $\mathrm{PM}_{10}$, are shown in Figs. 4 and 5. According to the predefined subregions as illustrated in Fig. 2, all simulations and observations are grouped into the five regions, with the modeling results sampled at the corresponding observation stations before averaging together.

The measured BC concentrations in Region_2 exhibit an obvious seasonal variation, with the minimum $\left(\sim 3.5 \mu \mathrm{g} \mathrm{m}^{-3}\right)$ in spring and summer, and the maximum $\left(\sim 8 \mu \mathrm{g} \mathrm{m}^{-3}\right)$ during late autumn and winter. Participant models can capture this seasonality quite well, and nearly all simulation results are within the standard deviation of the observations, but a large intermodel variation is also simulated, especially in winter when BC concentration is high. Due to its low reactivity in the atmosphere, this variation may be caused by their simulated meteorological conditions, including the impacts of different coupling ways between meteorological and chemical modules (Y. Gao et al., 2015). As Briant et al. (2017) and Huang et al. (2018) concluded, the online integrated models can simulate higher BC concentra- tions than offline models, especially during polluted periods. The correlation coefficient in MMEM is 0.73 .

For $\mathrm{PM}_{2.5}$, the observed monthly concentrations in $\mathrm{Re}$ gion_2 are higher than those in Region_1. This is because the emissions in China are larger than those in Japan and the Korean Peninsula (Fig. S2). But nearly all models tend to underpredict the concentrations of $\mathrm{PM}_{2.5}$ in Region_1, with NMBs ranging from $-44.3 \%$ (in winter) to $-22.7 \%$ (in summer) for MMEM. Comparing with the correlation coefficient ( $R=0.40$ ) in Region_1, CTMs can better reproduce the seasonality of the observed $\mathrm{PM}_{2.5}$ in Region_2, with the $R$ of 0.69 for MMEM. Generally, the $R$ for MMEM in Region_All is 0.83 and the NMB ranges from $-2.2 \%$ (in autumn) to $13.9 \%$ (in winter).

Similar temporal-variation characteristics of $\mathrm{PM}_{10}$ concentrations are observed in Region_1, Region_2, and Region_4, with the maximum occurring in March and November, and the minimum occurring during summer. Most models fall within the standard deviation of the observations. The simulated $\mathrm{PM}_{10}$ concentrations in Region_2 show less diversity, but nearly all models peak 2 months later. A distinctive seasonality can be found in Region_4, with the highest value (nearly $80 \mu \mathrm{g} \mathrm{m}^{-3}$ ) observed in March, but most models cannot reproduce this characteristic. This is because GFED substantially underestimates the biomass burning emissions over southeast Asia (Fu et al., 2012), especially during MarchApril when most intense biomass burning occurred in Myanmar, Thailand, and other southeast Asian countries (Huang et al., 2012), and the emission bias is mainly due to the lack of agricultural fires (Nam et al., 2010). Finally, a weak seasonality in $\mathrm{PM}_{10}$ is simulated by MMEM with $R$ of 0.58 in Region_4. In Region_All, although consistent underestimation is simulated during the whole period, with NMB ranging from $-40.8 \%$ to $-25.2 \%$ for MMEM, the seasonal cycle can be well reproduced by MMEM with $R$ of 0.78 .

The seasonal variation characteristics of observed $\mathrm{SO}_{4}^{2-}$, $\mathrm{NO}_{3}^{-}$and $\mathrm{NH}_{4}^{+}$in Region_1 are not obvious, with the annual mean of $\sim 4 \mu \mathrm{g} \mathrm{m}^{-3}$ for $\mathrm{SO}_{4}^{2-}, 1.5 \mu \mathrm{g} \mathrm{m}^{-3}$ for $\mathrm{NO}_{3}^{-}$, and $1.0 \mu \mathrm{g} \mathrm{m}^{-3}$ for $\mathrm{NH}_{4}^{+}$, respectively. A large intermodel spread of simulated $\mathrm{SO}_{4}^{2-}$ is shown in Fig. 5a1, with the maximum variation range in June. Most models significantly overpredict the observed $\mathrm{NO}_{3}^{-}$concentrations, especially in summer with the NMB of $164.3 \%$ for MMEM. Simulated monthly $\mathrm{NH}_{4}^{+}$concentrations from most models are within the standard deviation of observations, and the $R$ for MMEM is as high as 0.74 . In Region_2, the observations are only available at one EANET site (the Hongwen site, located in the eastern coastal area of China), and the seasonality of observed $\mathrm{SO}_{4}^{2-}, \mathrm{NO}_{3}^{-}$, and $\mathrm{NH}_{4}^{+}$from this station is obvious with the maximum in spring and winter, and the minimum in late summer and early autumn. Nearly all models tend to underpredict these concentrations, but the MMEM captures the seasonal cycle relative well with $R$ values of 0.57 for $\mathrm{SO}_{4}^{2-}$, 0.85 for $\mathrm{NO}_{3}^{-}$, and 0.86 for $\mathrm{NH}_{4}^{+}$, respectively. In Region_3, 

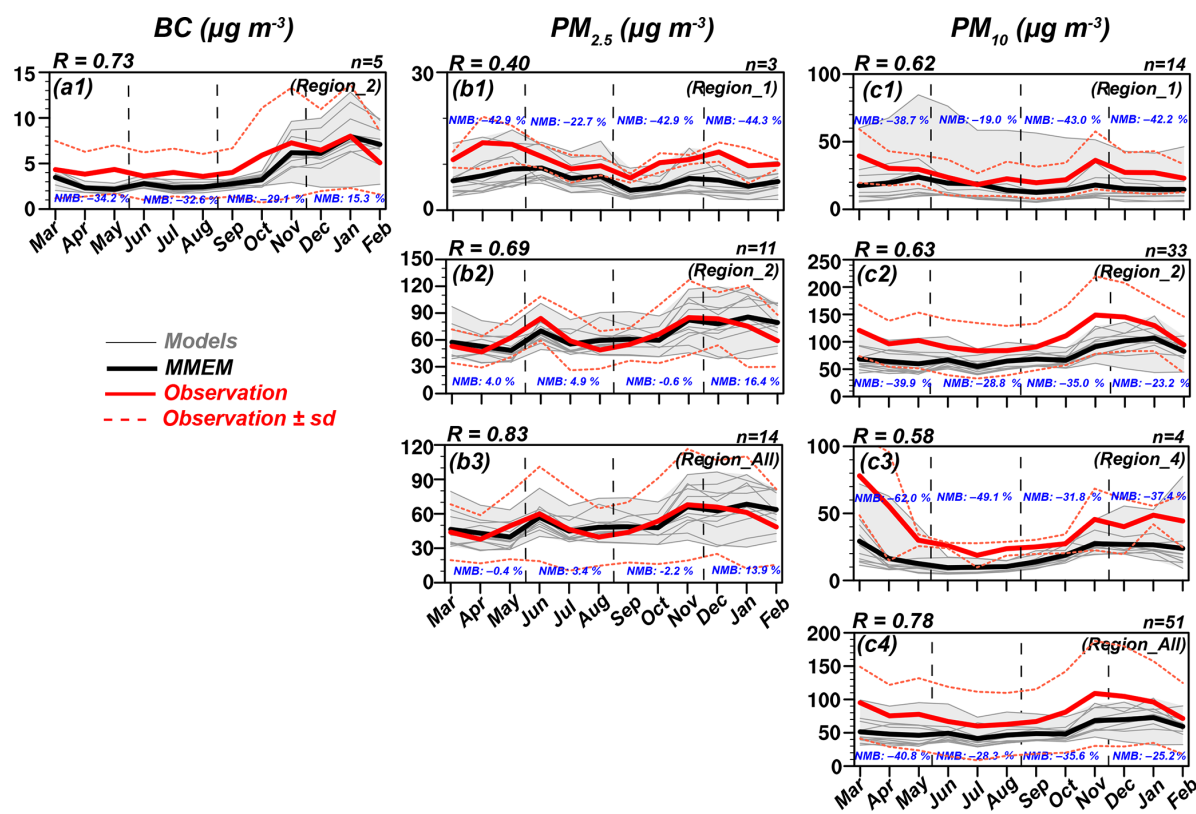

Figure 4. Time series of the monthly observed and simulated aerosol compositions: (a1) BC, (b1-b3) $\mathrm{PM}_{2.5}$, and (c1-c4) PM10. The thin grey lines represent simulation results, and the grey shaded areas indicate the spread. The thick black lines are the ensemble mean. The red solid lines mean the observations, and the dashed red lines represent 1 standard deviation. Correlation coefficients ( $R$ values, shown in black) for the whole year and normalized mean biases (NMBs, shown in blue) for each season between observations and MMEM are shown in each panel. The number of monitoring sites used to calculate the statistics in each subregion is also listed above each panel. In this figure, the monthly observations except BC are taken from EANET and CNEMC; the monthly BC concentrations are collected from published literature.

the observed maximum concentrations of $\mathrm{SO}_{4}^{2-}$ and $\mathrm{NH}_{4}^{+}$are in winter, but most models cannot reproduce the increasing tendency during the late autumn and the early winter, which means participant models fail to capture the seasonality $(R$ values of 0.20 for $\mathrm{SO}_{4}^{2-}, 0.34$ for $\mathrm{NO}_{3}^{-}$, and 0.18 for $\mathrm{NH}_{4}^{+}$, respectively). This may be due to the low emission of primary aerosols and their precursors in Region_3. Meanwhile, the Regional Emission Inventory in Asia (REAS v2.1) is used in Region_3, which is calculated based on the emissions from 2000 to 2008 (M. Li et al., 2017), not extended to the simulation year of 2010. The updated emissions with localized data may increase the accuracy of simulation results. In Region_4, the simulated concentrations of $\mathrm{SO}_{4}^{2-}, \mathrm{NO}_{3}^{-}$, and $\mathrm{NH}_{4}^{+}$are fairly good when compared with the measurements. The $R$ values of MMEM are 0.73 for $\mathrm{SO}_{4}^{2-}, 0.63$ for $\mathrm{NO}_{3}^{-}$, and 0.73 for $\mathrm{NH}_{4}^{+}$. Meanwhile, the model diversities are small. Generally, in Region_All, MMEM can well reproduce the magnitudes of observed $\mathrm{SO}_{4}^{2-}, \mathrm{NO}_{3}^{-}$, and $\mathrm{NH}_{4}^{+}$during the whole simulation period, as well as the seasonal variation characteristics.

As mentioned above, the observed monthly mean concentrations of aerosol compositions in China are only available at one EANET station (site 17, the Hongwen station), with missing values in June and October. In order to make the evaluation more comprehensive, observed seasonal mean concentrations of $\mathrm{SO}_{4}^{2-}, \mathrm{NO}_{3}^{-}$, and $\mathrm{NH}_{4}^{+}$collected from pub- lished literature are also used to compare with simulation results (Fig. S5). M2, M12, and M14 reasonably reproduce the $\mathrm{SO}_{4}^{2-}$ concentrations in the four seasons, while others fail to simulate the high observed $\mathrm{SO}_{4}^{2-}$ concentrations. The NMBs of $\mathrm{SO}_{4}^{2-}$ range from $-79.4 \%$ (M7) to $12.8 \%$ (M14). On the contrary, nearly all participant models overestimate the concentrations of $\mathrm{NO}_{3}^{-}$(except M4, M7, and M8), with NMBs ranging from $1.7 \%$ (M5) to $50.2 \%$ (M9). The underestimation of $\mathrm{SO}_{4}^{2-}$ and the overestimation of $\mathrm{NO}_{3}^{-}$may be the general performance in current CTMs (Y. Wang et al., 2013; Gao et al., 2014; Huang et al., 2014; Zheng et al., 2015), and some hypotheses should be deeply tested in the future to reduce these deviations, such as (1) missing oxidation mechanisms of $\mathrm{SO}_{2}$ may lead to low concentrations of $\mathrm{SO}_{4}^{2-}$, which allows for excess $\mathrm{NO}_{3}^{-}$in the presence of ammonia, and (2) there is an issue with $\mathrm{NO}_{x}$ partitioning and/or missing $\mathrm{NO}_{x}$ sink. Meanwhile, Seinfeld and Pandis (2006) pointed out that the chemical production of $\mathrm{SO}_{4}^{2-}$ and $\mathrm{NO}_{3}^{-}$ is mainly from the gas-phase and/or liquid-phase oxidation of $\mathrm{SO}_{2}$ and $\mathrm{NO}_{2}$. Therefore, further comparisons of observed and simulated $\mathrm{SO}_{2}$ and $\mathrm{NO}_{2}$ are shown in Figs. S6 and $\mathrm{S} 7$. From Fig. S6, participant models can generally reproduce the seasonality of the two gases, with $R$ values of 0.61 for $\mathrm{SO}_{2}$ and 0.65 for $\mathrm{NO}_{2}$, respectively. But overestimations (underestimations) of $\mathrm{SO}_{2}\left(\mathrm{NO}_{2}\right)$ are found during most simulation periods, not only in China but also in other defined subre- 

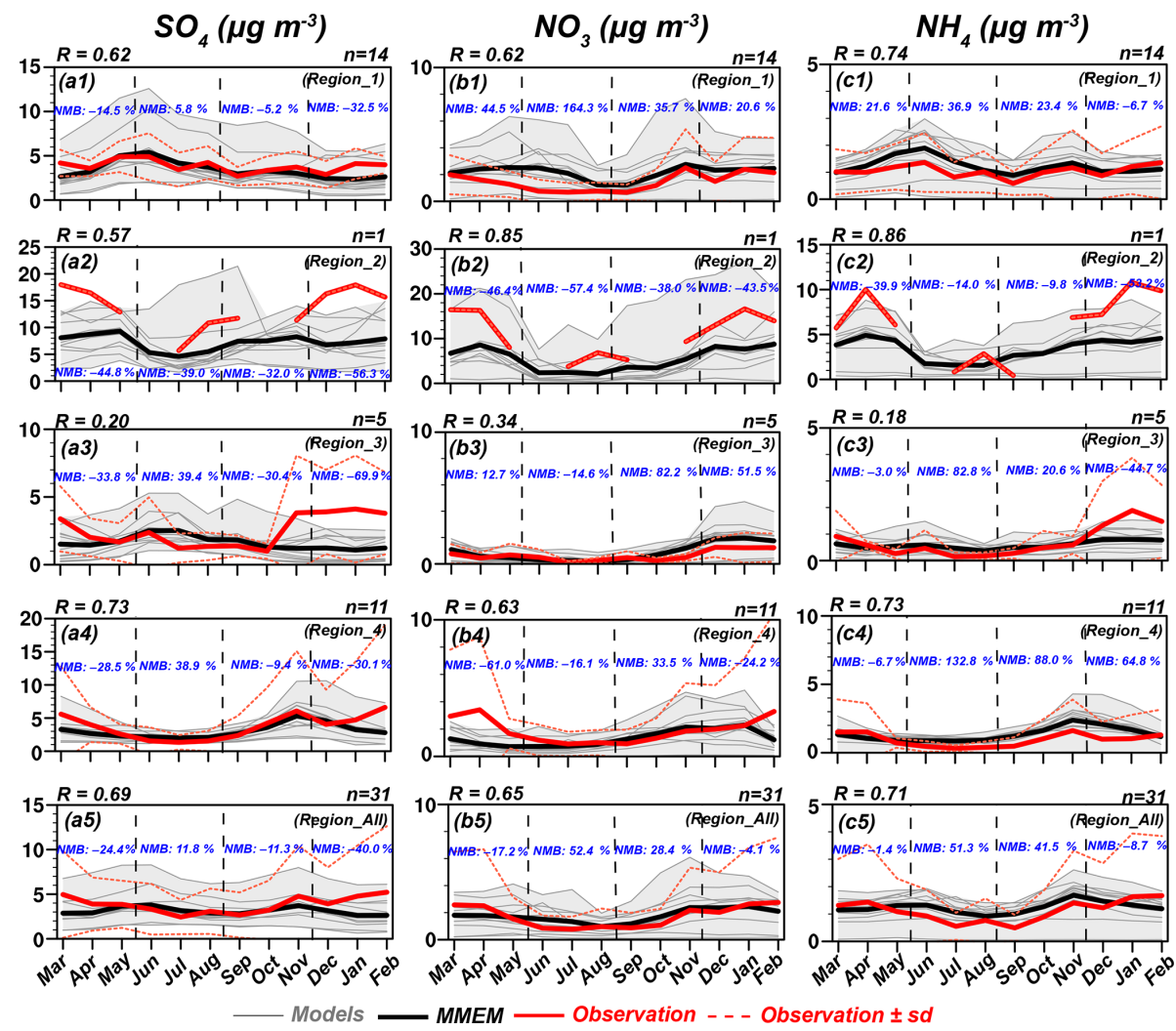

Figure 5. The same as Fig. 4 but for (a1-a5) $\mathrm{SO}_{4}^{2-}$, (b1-b5) $\mathrm{NO}_{3}^{-}$, and (c1-c5) $\mathrm{NH}_{4}^{+}$. In this figure, the monthly measurements are taken from EANET.

gions (Fig. S7). The overestimated (underestimated) concentrations of $\mathrm{SO}_{2}\left(\mathrm{NO}_{2}\right)$ can be used to explain the underestimation (overestimation) of simulated $\mathrm{SO}_{4}^{2-}\left(\mathrm{NO}_{3}^{-}\right)$. However, significant underestimation of $\mathrm{NO}_{3}^{-}$is also simulated by $\mathrm{M} 7$ and M8. As mentioned above, the extremely low concentrations of $\mathrm{NH}_{3}$ in $\mathrm{M} 7$ and $\mathrm{M} 8$ may be the main reason for this negative bias. Analyzing the results from ensemble mean, MMEM shows better performance than participating models, with $\mathrm{NMBs}$ of $-46.0 \%$ for $\mathrm{SO}_{4}^{2-}, 1.9 \%$ for $\mathrm{NO}_{3}^{-}$, and $13.1 \%$ for $\mathrm{NH}_{4}^{+}$, respectively.

\subsubsection{Evaluation for aerosol optical depth}

Simulated AODs at $550 \mathrm{~nm}$ from the nine participant models (M1, M2, M4, M7, M9, M11, M12, M13, and M14) are compared with the measurements from AERONET. From Fig. 6, we can find that most models tend to overpredict AOD values during the whole simulation period in Region_1, Region_2, and Region_3 with NMBs of $74.0 \%, 38.8 \%$, and $107.0 \%$ for MMEM, respectively. In Region_4, an obvious seasonality is observed, with the maximum in spring and the minimum in summer. Models can capture this seasonality well, although underestimation is found in spring. The $R$ for MMEM is 0.65 and the NMB is $-8.7 \%$ in Region_4. Smaller NMB $(-4.2 \%)$ is calculated in Region_5 by MMEM, but a quite weak seasonality is shown with underestimated AOD in spring and summer, and overestimated AOD in autumn and winter. Generally, simulated AOD values are within a standard deviation of the observations in Region_All, with a slight overestimation in autumn and winter. The MMEM can reproduce the seasonal cycle with $R$ of 0.68 , and the NMB for MMEM is $18.7 \%$.

Figure 7 presents the spatial distributions of the observed and simulated AOD at $550 \mathrm{~nm}$. MODIS AOD is collected from the Terra and Aqua satellites during the year 2010. The observed AODs from AERONET are also shown. In order to quantify the ability of each model to simulate the spatial distribution of aerosol particles, spatial correlation coefficients are also given in the bottom left corner of each panel. Analyzing the observations from MODIS, we can conclude that AOD values are higher in central and eastern China, including the Sichuan province, with the maximum over 1.0. High values can also be observed in the north of India. Due to dust events happening in arid and semi-arid regions, AOD values over the Taklimakan are also large $(\sim 0.5)$. Comparing with MODIS AOD, most models can reproduce the spatial distribution characteristics, with high values in China and India, and low values in other countries. The $R$ values range from 0.78 (M12) to 0.86 (M1, M11 and M13). But most models tend to underestimate the AOD in the eastern coastal regions 

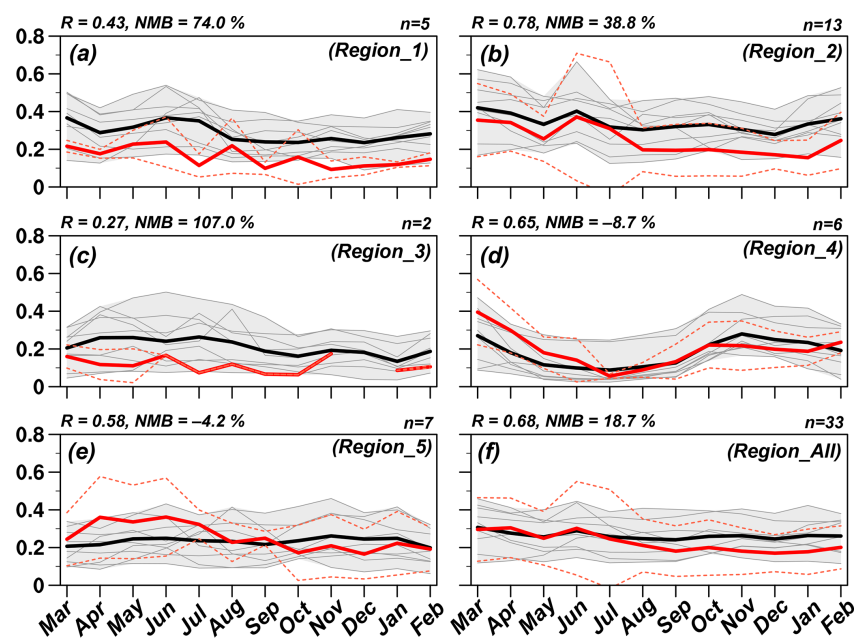

- Models — MMEM — Observation - - - - Observation \pm sd

Figure 6. Similar to Fig. 4 but for seasonal cycles of AOD at $550 \mathrm{~nm}$. In this figure, the monthly measurements are taken from AERONET.
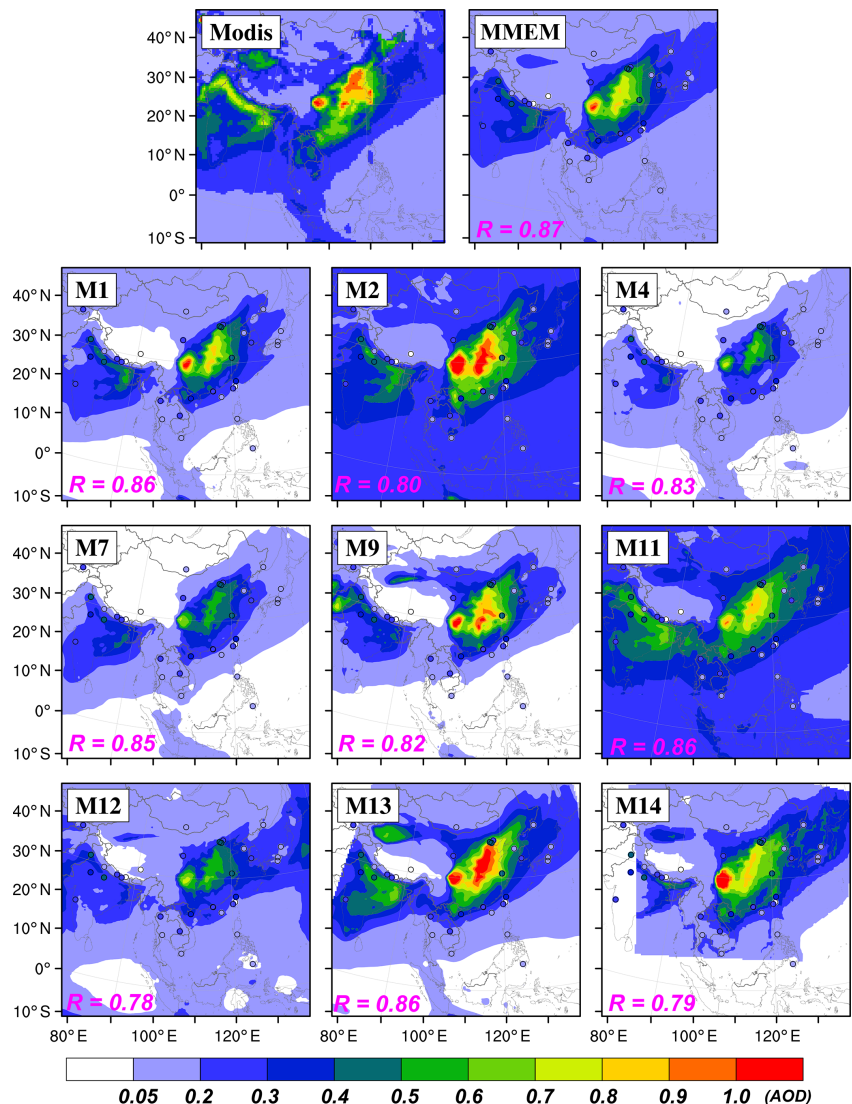

Figure 7. Spatial distributions of observed and simulated AODs at $550 \mathrm{~nm}$. The observed AOD values are retrieved from MODIS. Spatial correlation coefficients are given in the bottom left corner of each panel. Observed AODs from AERONET are also shown in circles. of China and the north regions of India (Fig. S8), where anthropogenic emissions are large. Meanwhile, dust particles can be frequently observed. Generally, MMEM captures the AOD spatial variation better with $R$ of 0.87 , and the mean bias is -0.08 .

\subsubsection{Statistics for aerosol particles and aerosol optical depth}

Table 2 shows the statistics of correlation coefficient $(R)$, normalized mean bias (NMB), and root mean squared error (RMSE) for $\mathrm{BC}, \mathrm{SO}_{4}^{2-}, \mathrm{NO}_{3}^{-}, \mathrm{NH}_{4}^{+}, \mathrm{PM}_{2.5}, \mathrm{PM}_{10}$, and AOD. Simulation results from participant models and MMEM are compared with available observations. Best results are in bold and underlined.

It can be found that participant models are able to capture the variability of $\mathrm{BC}$ in China, with $R$ values ranging from 0.65 (M5) to 0.80 (M8), but nearly all models tend to underestimate the $\mathrm{BC}$ concentration, except M1 and M2. The maximum negative deviation is simulated by M5 (NMB $=-54.9 \%$ ), while the maximum positive deviation is from M2 with NMB of $12.7 \%$. All the RMSEs are less than the observed mean concentration of $\mathrm{BC}\left(5.0 \mu \mathrm{g} \mathrm{m}^{-3}\right)$. Comparing to the observed $\mathrm{SO}_{4}^{2-}$, most models fail to reproduce the high values, and the NMB for MMEM is $-19.1 \%$, meaning the underestimation of the simulated $\mathrm{SO}_{4}^{2-}$ concentration is a general phenomenon in current CTMs. Implementing more detailed sulfate aerosol formation mechanisms (e.g., heterogeneous reaction and catalytic oxidation) into air quality models may improve the accuracy of simulation results (Huang et al., 2014; Zheng et al., 2015; Fu et al., 2016). But most models can capture the variation of $\mathrm{SO}_{4}^{2-}$ with $R$ values ranging from 0.46 (M14) to 0.76 (M13). For $\mathrm{NO}_{3}^{-}, R$ values vary from 0.29 (M8) to as high as 0.65 (MMEM). M5 shows the largest correlation (0.65) and the smallest NMB $(-1.7 \%)$ among models. Although a high value of $R(0.64)$ is calculated by M9, the NMB is the largest (125.7\%). All RMSEs are larger than the measured $\mathrm{NO}_{3}^{-}\left(1.7 \mu \mathrm{g} \mathrm{m}^{-3}\right)$, meaning a relative poor performance for current CTMs to simulate the $\mathrm{NO}_{3}^{-}$concentrations in East Asia. For $\mathrm{NH}_{4}^{+}$, underestimation can be found in M4, M7, and M8, while the others tend to overestimate the $\mathrm{NH}_{4}^{+}$concentration. Although all RMSEs are larger than the observed $\mathrm{NH}_{4}^{+}$(mean value is $1.1 \mu \mathrm{g} \mathrm{m}^{-3}$ ), most models can capture the variability, with $R$ values ranging from 0.34 (M8) to 0.75 (M9). Generally, MMEM matches the observations with $R$ of 0.71 , NMB of $14.0 \%$, and RMSE of $1.11 \mu \mathrm{g} \mathrm{m}^{-3}$, respectively. Although significant underprediction is found in $\mathrm{PM}_{10}$ (NMBs range from $-55.7 \%$ in M5 to $-16.9 \%$ in M9, except M14) and the intermodel spread is large in $\mathrm{PM}_{2.5}$ (NMBs range from $-26.5 \%$ in M13 to $46.0 \%$ in M14), the variations of simulated $\mathrm{PM}_{2.5}$ and $\mathrm{PM}_{10}$ are well correlated with measurements ( $R$ values $>0.60$ ) and the RMSEs are all smaller than the averaged concentrations $\left(51.4 \mu \mathrm{g} \mathrm{m}^{-3}\right.$ for $\mathrm{PM}_{2.5}, 80.7 \mu \mathrm{g} \mathrm{m}^{-3}$ for $\mathrm{PM}_{10}$ ). For AOD, large positive deviations are simulated 
Table 2. Statistics of $\mathrm{BC}, \mathrm{SO}_{4}^{2-}, \mathrm{NO}_{3}^{-}, \mathrm{NH}_{4}^{+}, \mathrm{PM}_{2.5}, \mathrm{PM}_{10}$, and AOD. Best results are in bold. Monthly mean observations and the number of stations (nstd) are in italic. In this table, monthly measurements except BC are taken from EANET, CNEMC, and AERONET. Monthly $\mathrm{BC}$ concentrations are collected from published literature.

\begin{tabular}{|c|c|c|c|c|c|c|c|c|c|c|c|c|c|c|}
\hline Species & Statistics & M1 & M2 & M4 & M5 & M6 & M7 & M8 & M9 & M11 & M12 & M13 & M14 & EM \\
\hline & $R$ & 0.70 & 0.73 & 0.71 & 0.65 & 0.70 & 0.73 & 0.80 & - & 0.69 & 0.68 & 0.75 & 0.72 & 0.73 \\
\hline$\left(5.0 \mu \mathrm{g} \mathrm{m}^{-3}\right)$ & $\operatorname{NMB}(\%)$ & 1.0 & 12.7 & -24.7 & -54.9 & -17.8 & -11.7 & -34.2 & - & -17.5 & -2.2 & -26.8 & -11.6 & -17.0 \\
\hline$(\mathrm{nstd}=5)$ & RMSE & 4.10 & 4.30 & 2.95 & 4.06 & 2.99 & 2.69 & 2.84 & - & 2.91 & 3.52 & 2.80 & 2.64 & 2.77 \\
\hline $\mathrm{SO}_{4}^{2-}$ & $R$ & 0.69 & 0.71 & 0.64 & 0.58 & 0.66 & 0.48 & 0.53 & 0.65 & 0.55 & 0.50 & 0.76 & 0.46 & 0.69 \\
\hline$\left(3.8 \mu \mathrm{g} \mathrm{m}^{-3}\right)$ & $\operatorname{NMB}(\%)$ & -23.1 & -13.0 & -31.0 & -26.4 & -26.9 & -67.7 & -1.6 & -67.0 & -34.5 & 23.2 & -31.9 & 69.3 & -19.1 \\
\hline$(\mathrm{nstd}=31)$ & RMSE & 3.21 & 3.00 & 3.46 & 3.57 & 3.35 & 4.64 & 3.62 & 4.45 & 3.78 & 4.01 & 3.24 & 5.51 & 3.22 \\
\hline $\mathrm{NO}_{3}^{-}$ & $R$ & 0.55 & 0.51 & 0.62 & 0.65 & 0.58 & 0.45 & 0.29 & 0.64 & 0.59 & 0.60 & 0.43 & 0.58 & 0.65 \\
\hline $1.7 \mu \mathrm{g} \mathrm{m}^{-3}$ & $\operatorname{NMB}(\%)$ & 9.0 & -7.2 & -42.7 & -1.7 & -11.8 & -81.2 & -80.6 & 125.7 & 46.5 & 54.0 & 22.7 & 35.4 & 4.9 \\
\hline$(\mathrm{nstd}=31)$ & RMSE & 2.70 & 2.71 & 2.48 & 2.29 & 2.46 & 3.37 & 3.18 & 4.37 & 2.89 & 2.80 & 2.96 & 2.62 & 2.27 \\
\hline $\mathrm{NH}_{4}^{+}$ & $R$ & 0.67 & 0.64 & 0.68 & 0.66 & 0.69 & 0.55 & 0.34 & 0.75 & 0.66 & 0.62 & 0.64 & 0.68 & 0.71 \\
\hline$\left(1.1 \mu \mathrm{g} \mathrm{m}^{-3}\right)$ & $\operatorname{NMB}(\%)$ & 23.2 & 33.7 & -10.6 & 7.4 & 14.6 & -93.5 & -34.2 & 45.3 & 35.0 & 49.9 & 34.9 & 56.3 & 14.0 \\
\hline$($ nstd $=31)$ & RMSE & 1.24 & 1.42 & 1.15 & 1.21 & 1.16 & 1.83 & 1.53 & 1.26 & 1.27 & 1.54 & 1.29 & 1.47 & 1.11 \\
\hline $\mathrm{PM}_{2.5}$ & $R$ & 0.80 & 0.78 & 0.80 & 0.71 & 0.80 & 0.80 & 0.77 & 0.82 & 0.80 & 0.78 & 0.75 & 0.81 & 0.83 \\
\hline$\left(51.4 \mu \mathrm{g} \mathrm{m}^{-3}\right)$ & $\operatorname{NMB}(\%)$ & 10.0 & 13.6 & -1.3 & -25.3 & -5.8 & -5.7 & -15.3 & 26.2 & 5.2 & 31.4 & -26.5 & 46.0 & 4.4 \\
\hline$(\mathrm{nstd}=14)$ & RMSE & 27.56 & 34.88 & 23.03 & 28.00 & 21.80 & 23.54 & 24.83 & 28.52 & 22.06 & 34.87 & 27.10 & 35.85 & 21.23 \\
\hline $\mathrm{PM}_{10}$ & $R$ & 0.75 & 0.74 & 0.74 & 0.65 & 0.75 & 0.70 & 0.70 & 0.66 & 0.78 & 0.82 & - & 0.63 & 0.78 \\
\hline$\left(80.7 \mu \mathrm{g} \mathrm{m}^{-3}\right)$ & $\operatorname{NMB}(\%)$ & -40.7 & -38.7 & -35.7 & -55.7 & -46.6 & -43.7 & -43.4 & -16.9 & -25.4 & -18 & - & 7.1 & -32.6 \\
\hline$(\mathrm{nstd}=51)$ & RMSE & 51.31 & 50.88 & 49.10 & 64.55 & 55.31 & 55.07 & 55.11 & 50.67 & 42.91 & 37.28 & - & 47.26 & 45.81 \\
\hline AOD & $R$ & 0 & 0.5 & & - & - & 0. & - & 0.60 & 0.69 & 0.66 & 0.71 & 0.57 & 0.68 \\
\hline & NMB & -2.0 & 63.7 & -28.5 & - & - & -21.8 & - & 11.1 & 73.1 & -6.2 & 47.1 & 36.7 & 18.7 \\
\hline$(\mathrm{nstd}=38)$ & RMSE & 0.15 & 0.22 & 0.16 & - & - & 0.18 & - & 0.19 & 0.22 & 0.13 & 0.25 & 0.22 & 0.14 \\
\hline
\end{tabular}

by M2, M9, M11, M13, and M14, but these models can reproduce the spatial-temporal variation characteristics relatively well with $R$ values larger than 0.5 . M4 and M7 show the large negative deviation with NMBs of $-28.5 \%$ and $-21.8 \%$, respectively. But their RMSEs are relatively small ( 0.16 for M4 and 0.18 for M7). Generally, the $R, \mathrm{NMB}$, and RMSE for MMEM are $0.68,18.7 \%$, and 0.14 , respectively.

\subsection{Intercomparison between MICS-Asia phase II and phase III}

The main purpose of MICS-Asia phase III topic 1 is to assess the ability of current multi-scale air quality models to reproduce the air-pollutant concentrations in East Asia. In order to reveal the improvements of the simulation ability in current CTMs, statistics (e.g., RMSE and $R$ ) for observed and simulated $\mathrm{SO}_{4}^{2-}, \mathrm{NO}_{3}^{-}$, and $\mathrm{NH}_{4}^{+}$from MICS-Asia phase II and phase III are compared in Fig. 8.

The statistics of MICS-Asia phase II are taken from Hayami et al. (2008). The observed monthly mean concentrations are monitored with high completeness at the 14 EANET stations in March, July, and December 2001, and March 2002, and the model-predicted monthly surface concentrations are from eight regional CTMs. Notably, $\mathrm{NO}_{3}^{-}$ and $\mathrm{NH}_{4}^{+}$used in Hayami et al. (2008) are total $\mathrm{NO}_{3}^{-}$(the combination of gaseous $\mathrm{HNO}_{3}$ and particulate $\mathrm{NO}_{3}^{-}$) and total $\mathrm{NH}_{4}^{+}$(the combination of gaseous $\mathrm{NH}_{3}$ and particulate
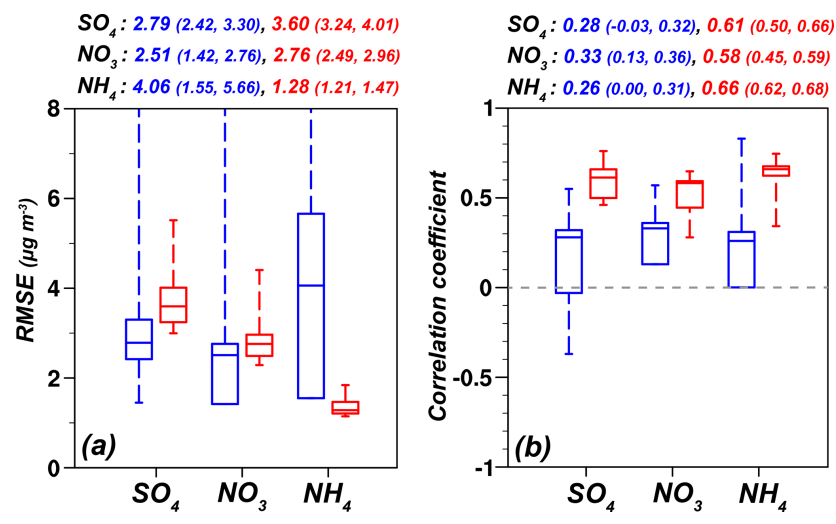

Figure 8. Intercomparison of model performance between MICSAsia phase II (blue) and phase III (red) for $\mathrm{SO}_{4}^{2-}, \mathrm{NO}_{3}^{-}$, and $\mathrm{NH}_{4}^{+}$. Detailed information about the observations and simulations used in phase II can be obtained from Hayami et al. (2008). Each box plot exhibits the full range, the interquartile range, and the median for the (a) RMSE and (b) correlation coefficient. Detailed values of the median (the 25 th percentile, the 75 th percentile) are also listed above each panel.

$\mathrm{NH}_{4}^{+}$), respectively. More detailed information can be found in Hayami et al. (2008).

Analyzing the RMSEs in Fig. 8, we can conclude that the medians (the 25 th percentile, the 75 th percentile) for $\mathrm{SO}_{4}^{2-}$, $\mathrm{NO}_{3}^{-}$, and $\mathrm{NH}_{4}^{+}$are $3.60(3.24,4.01), 2.76(2.49,2.96)$, and 
$1.28 \mu \mathrm{g} \mathrm{m}^{-3}\left(1.21,1.47 \mu \mathrm{g} \mathrm{m}^{-3}\right)$ in phase III, respectively. Although the medians (except $\mathrm{NH}_{4}^{+}$) are a little larger than that in phase II, the interquartile ranges are quite smaller, indicating similar concentrations can be simulated by current CTMs. Meanwhile, the medians of the correlations of $\mathrm{SO}_{4}^{2-}$, $\mathrm{NO}_{3}^{-}$, and $\mathrm{NH}_{4}^{+}$in phase III, including the upper and lower quartiles, are all larger than that in phase II, which means current CTMs show better performance in reproducing the spatial-temporal variations of observations.

Although the participating models (8 versus 12 CTMs), observation sites (14 versus 31 EANET stations), and simulation periods (4 months versus 1 year) are different between phase II and phase III, more reasonable statistics are calculated by current CTMs, reflecting better performance in simulating the concentrations of aerosols and their spatialtemporal variations.

\subsection{Intercomparison between participant models}

Figure 9 shows the spatial distributions of simulated $\mathrm{PM}_{2.5}$ concentrations from each participant model and the MMEM. The coefficient of variation (hereinafter, CV), defined as the standard deviation of the models divided by their mean, is also calculated. The larger the value of $\mathrm{CV}$, the lower the consistency among the participating models (Han et al., 2008; Gao et al., 2018). All simulation results can reproduce the high $\mathrm{PM}_{2.5}$ in the northern India and the eastern China, including the Sichuan province in China. The areas with high $\mathrm{PM}_{2.5}$ concentrations $\left(>40 \mu \mathrm{g} \mathrm{m}^{-3}\right.$ ) are consistent with the regions where $\mathrm{CV}$ is low $(<0.3)$, indicating similar performance of the CTMs in simulating the air pollutants over haze-polluted areas.

Previous studies have revealed that sulfate, nitrate, and ammonium (denoted as SNA) are the predominant inorganic aerosols in PM, and SNA can contribute to nearly half of the total $\mathrm{PM}_{2.5}$ mass (about 20\%-60\%) (Y. S. Wang et al., 2014; Sun et al., 2016b; Lin et al., 2018). All these show the necessity to exactly simulate the concentrations of SNA. Analyzing the mean ratio of SNA to $\mathrm{PM}_{2.5}$ averaged over the five defined subregions (Fig. 9), large variations are simulated by participant models, with values ranging from $31.1 \%$ (M7) to $75.1 \%$ (M5). Different gas-phase and aerosol chemistry mechanisms used in these CTMs can explain this inconsistency. The calculated SOR (sulfur oxidation ratio, $\mathrm{SOR}=n \mathrm{SO}_{4}^{2-} /\left(n \mathrm{SO}_{4}^{2-}+n \mathrm{SO}_{2}\right), n$ refers to the molar concentration), NOR (nitric oxidation ratio, NOR = $n \mathrm{NO}_{3}^{-} /\left(n \mathrm{NO}_{3}^{-}+n \mathrm{NO}_{2}\right)$, and PNR (particle neutralization ratio, $\mathrm{PNR}=n \mathrm{NH}_{4}^{+} /\left(2 \times n \mathrm{SO}_{4}^{2-}+n \mathrm{NO}_{3}^{-}\right)$are also obviously different.

SOR and NOR can be used to estimate the degree of secondary formation of $\mathrm{SO}_{4}^{2-}$ and $\mathrm{NO}_{3}^{-}$(Sun et al., 2006; Zhao et al., 2013). When SOR and NOR are less than 0.1, $\mathrm{SO}_{4}^{2-}$ and $\mathrm{NO}_{3}^{-}$mainly come from the primary source emissions; otherwise, high oxidation rates of SOR and NOR can result in large fractions of $\mathrm{SO}_{4}^{2-}$ and $\mathrm{NO}_{3}^{-}$in $\mathrm{PM}_{2.5}$ (Q. Fu et al.,
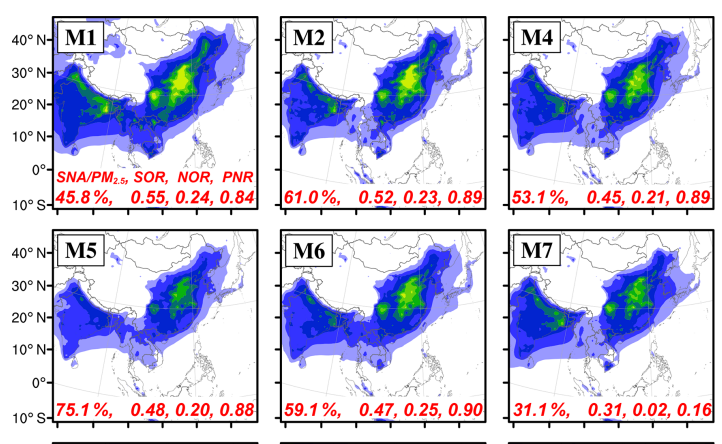

$\left(\mu g m^{-3}\right)$

500

200
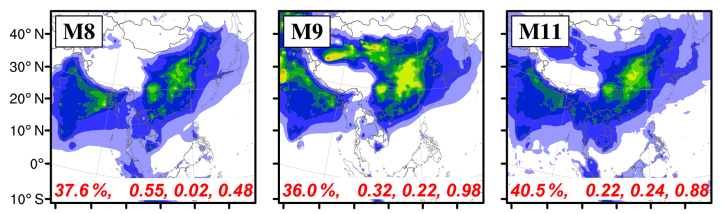

150

100

80

60
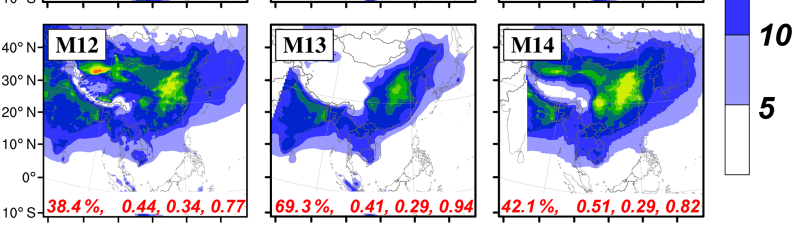

Mean (min, max)
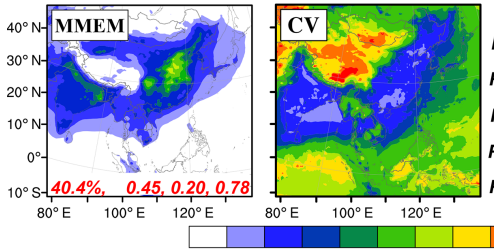

Region_1 : $C V=0.40(0.18,0.60)$

Region_2 : $\mathrm{CV}=0.80(0.14,2.95)$

Region_3 : $C V=0.75(0.21,2.28)$

Region_4 : $C V=0.63(0.18,2.29)$

Region_ $5: C V=0.31(0.15,1.38)$

${ }_{30^{\circ} \mathrm{E}}{ }_{100^{\circ} \mathrm{E}}{ }_{120^{\circ} \mathrm{E}}$

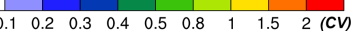

Figure 9. Spatial distributions of simulated $\mathrm{PM}_{2.5}$ concentrations from each participant model and the MMEM. The calculated coefficient of variation ( $\mathrm{CV}$, standard deviation divided by the mean) is also shown. The values listed in the bottom right corner of the figure represent the averaged $\mathrm{CV}$ (the minimum $\mathrm{CV}$, the maximum $\mathrm{CV}$ ) in each defined subregion. The ratio of SNA (sulfate, nitrate, and ammonium) to $\mathrm{PM}_{2.5}$, the SOR (sulfur oxidation ratio), the NOR (nitric oxidation ratio), and the PNR (particle neutralization ratio) are also given at the bottom of each panel.

2008). Generally, CMAQ models (M1, M2, M4, M5, M6 and M14) produce $30.7 \%$ higher SOR than others (except M8), which means more intense secondary formation of $\mathrm{SO}_{4}^{2-}$ is simulated by CMAQ. Similar NOR is predicted by participant models $(\sim 0.24)$, except M7 and M8. The extremely low value of NOR $(\sim 0.02)$ from M7 and M8 is due to the unreasonably low $\mathrm{NO}_{3}^{-}$concentrations. Previous measurements show that the mean value of NOR is about 0.15 (Du et al., 2011; Zhang et al., 2018), which is lower than the predicted one from MMEM (0.20) in this study, indicating more $\mathrm{NO}_{3}^{-}$ is produced by secondary formation in current CTMs.

PNR is defined as the mole ratio of ammonium to sulfate and nitrate. When PNR is larger than unity, sufficient ammonia can be used to neutralize the acidic sulfate and nitrate; otherwise, there is an incomplete neutralization of acidic species. Analyzing the calculated PNRs from partic- 


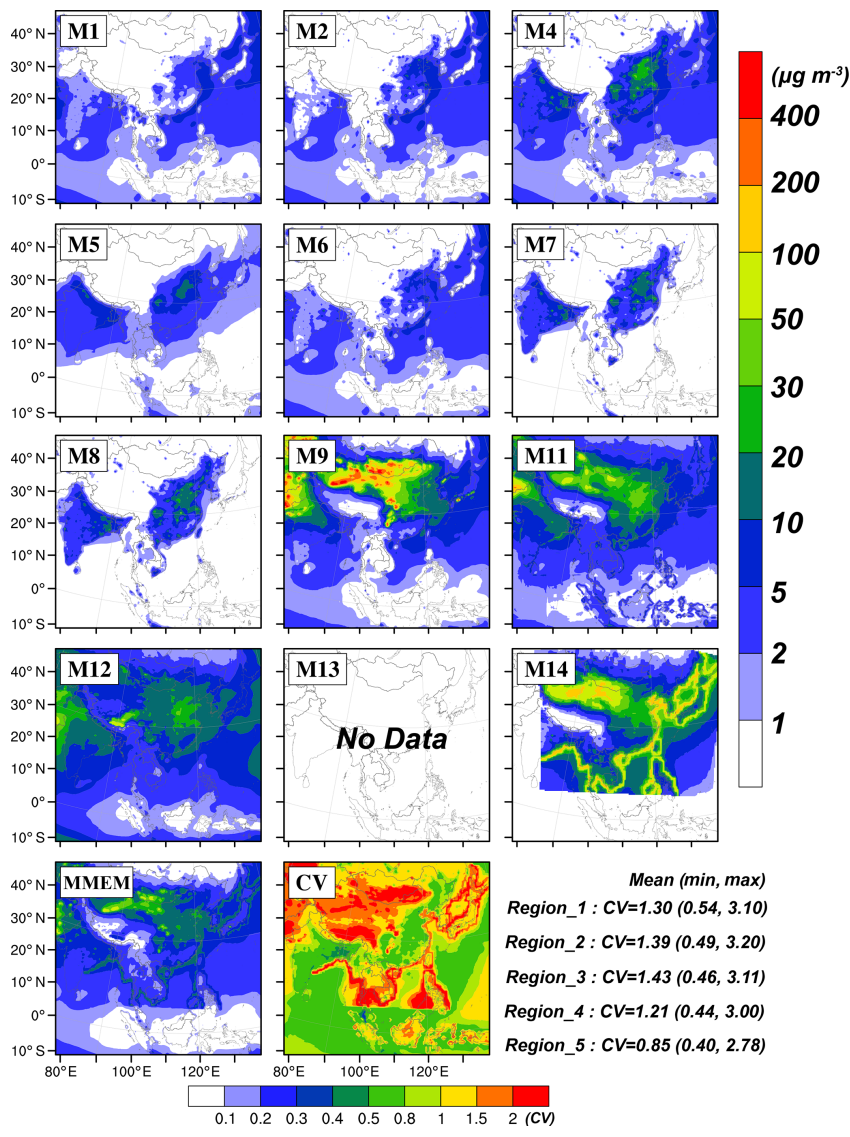

Figure 10. The same as Fig. 9 but for $\mathrm{PM}_{\text {coarse (coarse particles, }}$ subtract $\mathrm{PM}_{2.5}$ from $\mathrm{PM}_{10}$ ).

ipant models, all values are smaller than 1 , which means atmospheric conditions are considered to be ammonia deficient. But the mole ratios of $n \mathrm{NH}_{4}^{+} /\left(2 \times n \mathrm{SO}_{4}^{2-}\right)$ are all larger than $1(\sim 1.6$, except M7 and M8). All these indicate that acidic sulfate is fully neutralized to form $\left(\mathrm{NH}_{4}\right)_{2} \mathrm{SO}_{4}$ or $\mathrm{NH}_{4} \mathrm{HSO}_{4}$, and parts of acidic nitrate are changed to $\mathrm{NH}_{4} \mathrm{NO}_{3}$. Meanwhile, under $\mathrm{NH}_{3}$-limited conditions, small reductions in ammonia may cause significant reductions in particulate matter (Makar et al., 2009).

However, a large CV (>1.0) is simulated over arid and semi-arid regions (Fig. 9), such as the Taklimakan Desert and the Gobi Desert, where dust events are often observed, which means current CTMs have difficulty processing dust aerosols, especially in producing a similar amount of dust emissions and in identifying the same potential dust source regions, by using different dust schemes. Large CVs are also shown in simulated coarse particles (subtract $\mathrm{PM}_{2.5}$ from $\mathrm{PM}_{10}$ ) in Fig. 10. High concentrations of coarse particles simulated by M9 over arid and semi-arid regions may be caused by the inaccurate physicochemical parameters (e.g., plastic pressure of the soil surface) used in the Shao dust scheme (Kang et al., 2011). Large values $\left(>20 \mu \mathrm{g} \mathrm{m}^{-3}\right.$ ) over coastal regions from M14 may result from the inadequate simulation results of sea-salt aerosols.

From Table 3 we can conclude that the low consistency (or the large CV) of simulated coarse particles in each defined subregion is mainly caused by the dust particles. Without the impacts of dust aerosols and sea salts (only simulation results from $\mathrm{M} 7$ and $\mathrm{M} 8$ are considered), the calculated CVs for Region_1 to Region_5 are $0.29,0.30,0.33,0.19$, and 0.10 , respectively. Without the impacts of dust aerosols (only simulation results from M1, M2, M4, M5, and M6 are considered), similar spatial distributions are found in Fig. 10, and the CVs averaged over each subregion are 0.37 (Region_1), 0.65 (Region_2), 0.48 (Region_3), 0.59 (Region_4), and 0.65 (Region_5), respectively. But when the influences of dust aerosols and sea salts are both considered (simulation results from M9, M11, M12, and M14 are used), larger CVs are obtained with values of 0.97 for Region_1, 1.04 for Region_2, 1.27 for Region_3, 0.95 for Region_4, and 0.88 for Region_5.

Aerosol chemical compositions simulated by each participant model and the MMEM in the six metropolitan cities (Beijing, Shanghai, Guangzhou, Delhi, Seoul, and Tokyo) are shown in Fig. 11. $\mathrm{PM}_{2.5}$ is composed of SNA $\left(\mathrm{SO}_{4}^{2-}+\mathrm{NO}_{3}^{-}+\mathrm{NH}_{4}^{+}\right)$and OTHER1 $(\mathrm{BC}+\mathrm{OC}+\mathrm{OTHER} 2) . \mathrm{PM}_{10}$ includes $\mathrm{PM}_{2.5}$ and $\mathrm{PM}_{\text {coarse }}$ (coarse particles). Notably, $\mathrm{PM}_{\text {coarse }}$ cannot be calculated by M13 because $\mathrm{PM}_{10}$ is missing in M13.

High values of $\mathrm{PM}_{2.5}$ and $\mathrm{PM}_{10}$ in Beijing, Shanghai, Guangzhou, and Delhi are simulated by nearly all models, and the annual mean concentrations of $\mathrm{PM}_{2.5}$ and $\mathrm{PM}_{10}$ from MMEM are all larger than the IT-1 (interim target $1,35 \mu \mathrm{g} \mathrm{m}^{-3}$ for $\mathrm{PM}_{2.5}$ and $70 \mu \mathrm{g} \mathrm{m}^{-3}$ for $\mathrm{PM}_{10}$ ) proposed by WHO. But relatively small concentrations are presented in Tokyo (15.5 and $21.3 \mu \mathrm{g} \mathrm{m}^{-3}$ for $\mathrm{PM}_{2.5}$ and $\mathrm{PM}_{10}$, respectively) and Seoul (21.7 and $27.6 \mu \mathrm{g} \mathrm{m}^{-3}$ for $\mathrm{PM}_{2.5}$ and $\mathrm{PM}_{10}$, respectively). For each city, a large spread of concentrations of aerosol compositions can be found among participant models (a factor of $\sim 10$ for SNA, a factor of $\sim 2$ for $\mathrm{PM}_{2.5}$ and $\left.\mathrm{PM}_{10}\right)$. This is partly caused by the differences in gas-aerosol partitioning and dust emissions, including the removal processes (e.g., dry and wet depositions).

Analyzing the ratios of aerosol compositions to $\mathrm{PM}_{2.5}$ in MMEM (Fig. 11b1-b6), the sums of the contributions of $\mathrm{BC}, \mathrm{OC}, \mathrm{SO}_{4}^{2-}, \mathrm{NO}_{3}^{-}$, and $\mathrm{NH}_{4}^{+}$in Beijing $(63.8 \%)$, Shanghai $(60.4 \%)$, Guangzhou (63.1\%), and Delhi (65.1\%) are all less than those in Tokyo $(87.2 \%)$ and Seoul $(75.2 \%)$. Among these components, $\mathrm{NO}_{3}^{-}$is the major species in Beijing $(20.7 \%)$ and Delhi $(23.6 \%)$, while $\mathrm{SO}_{4}^{2-}$ is the major species in Guangzhou (22.2\%). Similar contributions of $\mathrm{SO}_{4}^{2-}$ and $\mathrm{NO}_{3}^{-}$can be found in Shanghai, Seoul, and Tokyo. All these suggest that different air-pollution control plans should be taken in different metropolitan cities.

For seasonal variations of $\mathrm{PM}_{2.5}$ concentrations (Fig. 11c1-c6), the highest values in Beijing $\left(107.6 \mu \mathrm{g} \mathrm{m}^{-3}\right)$, 
Table 3. The CV (standard deviation divided by the mean) of simulated coarse particles (subtract $\mathrm{PM}_{2.5}$ from $\mathrm{PM}_{10}$ ) in each defined subregion.

\begin{tabular}{lrrrr}
\hline CV & Normal $^{\mathrm{a}}$ & Without_SS_Dust $^{\mathrm{b}}$ & Without_Dust $^{\mathrm{c}}$ & With_SS_Dust $^{\mathrm{d}}$ \\
\hline Region_1 & 1.3 & 0.29 & 0.37 & 0.97 \\
Region_2 & 1.39 & 0.3 & 0.65 & 1.04 \\
Region_3 & 1.43 & 0.33 & 0.48 & 1.27 \\
Region_4 & 1.21 & 0.19 & 0.59 & 0.95 \\
Region_5 & 0.85 & 0.09 & 0.65 & 0.88 \\
\hline
\end{tabular}

a "Normal" means that simulation results from all participant models are considered. b "Without_SS_Dust" means that the impacts of sea-salt and dust aerosols are not considered; i.e., only simulation results from M7 and M8 are used to calculate the CV. " "Without_Dust" means that the impacts of dust aerosols are not considered; i.e., only simulation results from M1, M2, M4, M5, and M6 are used to calculate the CV.

d "With_SS_Dust" means that both the impacts of sea-salt and dust aerosols are considered; i.e., simulation results from M9, M11, M12, and M14 are used to calculate the CV.

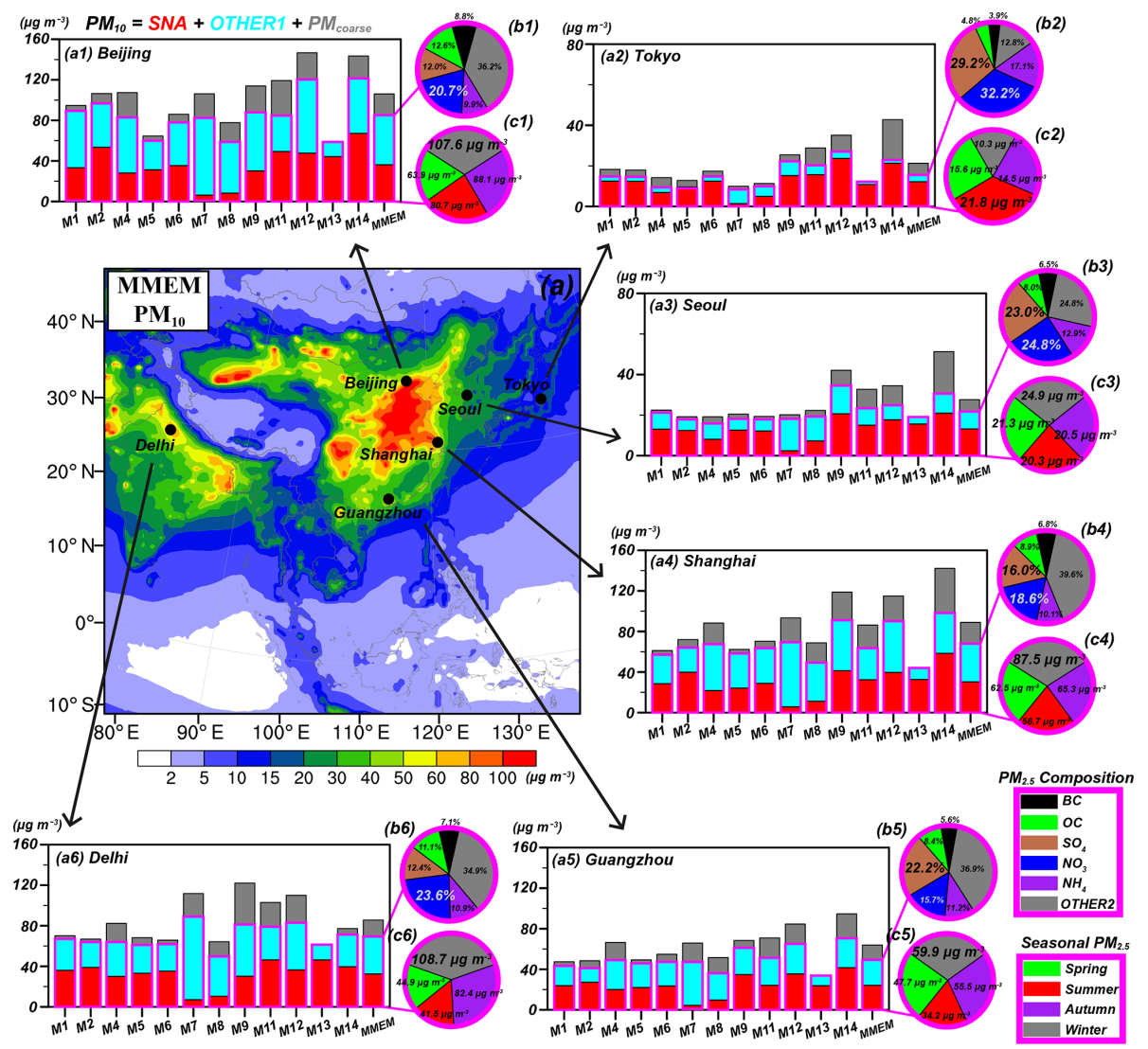

Figure 11. (a) The spatial distributions of $\mathrm{PM}_{10}$ concentrations for MMEM. (a1-a6) Simulated aerosol chemical compositions for participant models and the MMEM in the six metropolitan cities (Beijing, Tokyo, Seoul, Shanghai, Guangzhou, and Delhi). (b1b6) The ratios of each composition to $\mathrm{PM}_{2.5}$ for MMEM. (c1-c6) The seasonal $\mathrm{PM}_{2.5}$ concentrations for MMEM. It is noted that $\mathrm{PM}_{10}=\mathrm{SNA}+\mathrm{OTHER} 1+\mathrm{PM}_{\mathrm{coarse}}, \mathrm{SNA}=\mathrm{SO}_{4}^{2-}+\mathrm{NO}_{3}^{-}+\mathrm{NH}_{4}^{+}$, and OTHER1 $=\mathrm{BC}+\mathrm{OC}+\mathrm{OTHER} 2$.

Shanghai $\left(87.5 \mu \mathrm{g} \mathrm{m}^{-3}\right)$, Guangzhou $\left(59.9 \mu \mathrm{g} \mathrm{m}^{-3}\right)$, and Delhi $\left(108.7 \mu \mathrm{g} \mathrm{m}^{-3}\right)$ are all simulated in winter. This can be explained by their high emissions during this season. However, in Tokyo, the highest $\mathrm{PM}_{2.5}$ concentration is in summer $\left(21.8 \mu \mathrm{g} \mathrm{m}^{-3}\right)$ and the lowest value is in winter $\left(10.3 \mu \mathrm{g} \mathrm{m}^{-3}\right)$. In Seoul, $\mathrm{PM}_{2.5}$ concentrations are comparable during the four seasons.

\section{Conclusion and discussion}

This paper mainly focuses on the first topic of the MICSAsia phase III, and intends to analyze the following objectives: (1) provide a comprehensive evaluation of current air quality models against observations, (2) analyze the diversity of simulated aerosols among participant models, and (3) re- 
veal the characteristics of aerosol components in large cities over East Asia.

Comparisons against monthly observations from EANET and CNEMC demonstrate that all participant models can well reproduce the spatial-temporal distributions of aerosols. The MMEM shows better performance than most singlemodel predictions, with correlation coefficients $(R$ values, between MMEM and measurements) ranging from 0.65 (nitrate, $\left.\mathrm{NO}_{3}^{-}\right)$to $0.83\left(\mathrm{PM}_{2.5}\right)$. Differences between predictions and observations are also simulated; for instance, sulfate $\left(\mathrm{SO}_{4}^{2-}\right)$ is underestimated by participant models (except M12 and M14), with NMBs ranging from $-67.7 \%$ (M7) to $-1.6 \%$ (M8). The concentrations of nitrate $\left(\mathrm{NO}_{3}^{-}\right)$and ammonium $\left(\mathrm{NH}_{4}^{+}\right)$are overestimated by most models, with NMBs of $4.9 \%$ for $\mathrm{NO}_{3}^{-}$and $14.0 \%$ for $\mathrm{NH}_{4}^{+}$in MMEM. The absence of sulfate formation mechanisms (e.g., heterogeneous chemistry) in CTMs can be used to explain the underestimation of $\mathrm{SO}_{4}^{2-}$, and the underestimated $\mathrm{SO}_{4}^{2-}$ will result in the overestimation of $\mathrm{NO}_{3}^{-}$. However, significant underestimations of $\mathrm{NO}_{3}^{-}$and $\mathrm{NH}_{4}^{+}$are shown in $\mathrm{M} 7$ and M8. This is because extremely low values of $\mathrm{NH}_{3}$ are simulated by these models. The intermodel spread of simulated $\mathrm{PM}_{2.5}$ is large, with NMBs ranging from $-26.5 \%$ (M13) to $46.0 \%$ (M14), and nearly all models underestimate the $\mathrm{PM}_{2.5}$ concentrations in Region_1. The underestimation may be the insufficient precursors and formation pathways of organic aerosols in current CTMs. Underestimations of $\mathrm{PM}_{10}$ are also simulated in each subregion, and the NMB is $-32.6 \%$ in MMEM. This may due to the inaccurate emission inventories (e.g., anthropogenic emissions, biomass burning emissions, and natural emissions) considered in CTMs.

In order to reveal the improvements of the simulation ability in current CTMs, statistics for observed and simulated $\mathrm{SO}_{4}^{2-}, \mathrm{NO}_{3}^{-}$, and $\mathrm{NH}_{4}^{+}$from MICS-Asia phase II and phase III are compared. Results obviously show that the spread of RMSEs for each species in phase III is smaller, meaning similar concentrations can be simulated by current CTMs. Meanwhile, the medians of the correlations, including the upper and lower quartiles, are larger, which means current CTMs show better performance in reproducing the temporal variations of observations.

Analyzing the ratio of SNA to $\mathrm{PM}_{2.5}$, large variations are simulated by participant models, with values ranging from $31.1 \%$ (M7) to $75.1 \%$ (M5). Different gas-phase and aerosol schemes used in CTMs can explain this inconsistency. Higher SOR (sulfur oxidation ratio) is calculated by CMAQ models, indicating that CMAQ has a more intense secondary formation of $\mathrm{SO}_{4}^{2-}$ than other participant models. Similar NOR (nitric oxidation ratio) is predicted by CTMs, but the value $(\sim 0.20)$ is larger than the observed one $(\sim 0.15)$, which means overmuch $\mathrm{NO}_{3}^{-}$is simulated by current CTMs. According to the mole ratio of ammonium to sulfate and nitrate, $\mathrm{NH}_{3}$-limited condition can be successfully simulated by all participant models, which indicates that a small reduction in ammonia may improve the air quality significantly.

The coefficient of variation $(\mathrm{CV})$ can be used to quantify the intermodel deviation, and a large $\mathrm{CV}$ is shown in simulated coarse particles (subtract $\mathrm{PM}_{2.5}$ from $\mathrm{PM}_{10}$ ). The poor consistency, especially over the arid and semi-arid regions, is mainly caused by the dust aerosols, which means current CTMs have difficulty reproducing similar dust emissions by using different dust schemes. But the simulated fine particles are in good agreement, especially over the haze-polluted areas.

According to the MMEM simulation results, the highest $\mathrm{PM}_{2.5}$ concentrations in Beijing, Shanghai, Guangzhou, and Delhi are shown in winter, mainly due to the high emissions and unfavorable weather conditions. But the highest value in Tokyo appears in summer. $\mathrm{PM}_{2.5}$ concentrations are comparable in the four seasons in Seoul. Analyzing the ratios of each composition to $\mathrm{PM}_{2.5}, \mathrm{NO}_{3}^{-}$is the major component in Beijing and Delhi, $\mathrm{SO}_{4}^{2-}$ is the major one in Guangzhou, and similar contributions of $\mathrm{SO}_{4}^{2-}$ and $\mathrm{NO}_{3}^{-}$are calculated in Shanghai, Seoul, and Tokyo. All these suggest that different air-pollution control plans should be taken in different cities.

The MICS-Asia project gives an opportunity to understand the performance of CTMs in East Asian applications, including the similarities and differences among air quality models. In order to quantify the impacts of different model inputs and model configurations, and to reduce the diversities among simulation results, more detailed sensitivity experiments should be discussed. For example, simulation results from M1 and M2 can be used to assess the impacts of boundary conditions, since the configurations in these two models are similar except the boundary conditions. M1 adopts the downscale results from GEOS-Chem, while M2 uses the default values from CMAQ. From Fig. S9, we can find that positive biases are simulated $((\mathrm{M} 1-\mathrm{M} 2) / \mathrm{M} 2 \cdot 100 \%>0)$, especially around the edges of the simulation domain, and the maximum deviation can be over $100 \%$. This is because the boundary conditions from GEOS-Chem consider the impacts of aerosols outside the domain. All these demonstrate that the impacts of boundary conditions should not be neglected when analyzing the spatial distribution characteristic of simulated aerosols around the edge of the domain. But in most inland regions, differences between M1 and M2 are smaller $(< \pm 10 \%)$. Meanwhile, process analysis techniques (i.e., integrated process rate (IPR) analysis) should be developed and implemented in air quality models. This is because IPR can be used to calculate the contributions of each phys$\mathrm{ical} /$ chemical process to variations in aerosol concentrations (Chen et al., 2019); then it will be easier to draw conclusions about the fundamental problems that cause the differences between model predictions (Carmichael et al., 2008). Fully understanding of the source-receptor relationship in each process for a given aerosol species can also be helpful to revise parameterization schemes for better simulation 
capability. What is more, extensive observations should be collected and used in the next MICS-Asia project.

Data availability. Monthly pollution concentrations at EANET stations can be collected from https://monitoring.eanet.asia/document/ public/index (last access: 11 September 2019). The AERONET level 2.0 AOD data are downloaded from https://aeronet.gsfc.nasa. gov/cgi-bin/draw_map_display_aod_v3 (last access: 11 September 2019). The MODIS AOD data are available at https://ladsweb. modaps.eosdis.nasa.gov/search/order/1/MOD08_M3--61 (last access: 11 September 2019). Simulation results from the 14 participating models to generate figures and tables in this paper have been archived by corresponding authors and are available at https://pan. baidu.com/s/1IaaCDhrAR-z2tO6yQNz2cg (last access: 11 September 2019).

Supplement. The supplement related to this article is available online at: https://doi.org/10.5194/acp-19-11911-2019-supplement.

Author contributions. LC, YG, and MZ conducted the study design. LC, JZ, HL, JL, KH, BG, XW, YFL, CL, SI, TN, MK, and KY contributed to modeling data. JSF, ZW, and JK provided the emission data and observation data. YG and JZ helped with data processing. MZ, JSF, and JZ were involved in the scientific interpretation and discussion. LC prepared the manuscript with contributions from all co-authors.

Competing interests. The authors declare that they have no conflict of interest.

Special issue statement. This article is part of the special issue "Regional assessment of air pollution and climate change over East and Southeast Asia: results from MICS-Asia Phase III". It is not associated with a conference.

Acknowledgements. The authors thank the anonymous reviewers for their helpful comments that improved the paper.

Financial support. This research has been supported by the National Key R\&D Programs of China (2017YFB0503901 \& 2016YFA0600203), the National Natural Science Foundation of China (41830109, $91544221 \& 91644215)$, the University Natural Science Research Foundation of Jiangsu Province (18KJB170012), the Environment Research and Technology Development Fund (S12-1) of the Ministry of the Environment, Japan, the Startup Foundation for Introducing Talent of NUIST (2018r007), and the Decision-making Consultation Research Foundation of RICEG, NUIST (2018B33).
Review statement. This paper was edited by Gregory R. Carmichael and reviewed by two anonymous referees.

\section{References}

Ackermann, I. J., Hass, H., Memmesheimer, M., Ebel, A., Binkowski, F. S., and Shankar, U. M. A.: Modal aerosol dynamics model for Europe: Development and first applications, Atmos. Environ., 32, 2981-2999, https://doi.org/10.1016/S13522310(98)00006-5, 1998.

Ahmadov, R., McKeen, S. A., Robinson, A., Bahreini, R., Middlebrook, A., de Gouw, J., Meagher, J., Hsie, E., Edgerton,E., Shaw, S., and Trainer, M.: A volatility basis set modelfor summertime secondary organic aerosols over the eastern United States in 2006, J. Geophys. Res., 117, D06301, https://doi.org/10.1029/2011JD016831, 2012.

Appel, K. W., Pouliot, G. A., Simon, H., Sarwar, G., Pye, H. O. T., Napelenok, S. L., Akhtar, F., and Roselle, S. J.: Evaluation of dust and trace metal estimates from the Community Multiscale Air Quality (CMAQ) model version 5.0, Geosci. Model Dev., 6, 883-899, https://doi.org/10.5194/gmd-6-883-2013, 2013.

Archer-Nicholls, S., Lowe, D., Utembe, S., Allan, J., Zaveri, R. A., Fast, J. D., Hodnebrog, Ø., Denier van der Gon, H., and McFiggans, G.: Gaseous chemistry and aerosol mechanism developments for version 3.5 .1 of the online regional model, WRF-Chem, Geosci. Model Dev., 7, 2557-2579, https://doi.org/10.5194/gmd-7-2557-2014, 2014.

Baklanov, A., Schlünzen, K., Suppan, P., Baldasano, J., Brunner, D., Aksoyoglu, S., Carmichael, G., Douros, J., Flemming, J., Forkel, R., Galmarini, S., Gauss, M., Grell, G., Hirtl, M., Joffre, S., Jorba, O., Kaas, E., Kaasik, M., Kallos, G., Kong, X., Korsholm, U., Kurganskiy, A., Kushta, J., Lohmann, U., Mahura, A., Manders-Groot, A., Maurizi, A., Moussiopoulos, N., Rao, S. T., Savage, N., Seigneur, C., Sokhi, R. S., Solazzo, E., Solomos, S., Sørensen, B., Tsegas, G., Vignati, E., Vogel, B., and Zhang, Y.: Online coupled regional meteorology chemistry models in Europe: current status and prospects, Atmos. Chem. Phys., 14, 317-398, https://doi.org/10.5194/acp-14-317-2014, 2014.

Balzarini, A., Pirovano, G., Honzak, L., Žabkar, R., Curci, G., Forkel, R., Hirtl, M., San José, R., Tuccella, P., and Grell, G. A.: WRF-Chem model sensitivity to chemical mechanisms choice in reconstructing aerosol optical properties, Atmos. Environ., 115, 604-619, https://doi.org/10.1016/j.atmosenv.2014.12.033, 2014.

Bey, I., Jacob, D. J., Yantosca, R. M., Logan, J. A., Field, B. D., Fiore, A. M., Li, Q., Liu, H. Y., Mickley, L. J., and Schultz, M. G.: Global modeling of tropospheric chemistry with assimilated meteorology: Model description and evaluation, J. Geophys. Res.-Atmos., 106, 23073-23095, https://doi.org/10.1029/2001jd000807, 2001.

Briant, R., Tuccella, P., Deroubaix, A., Khvorostyanov, D., Menut, L., Mailler, S., and Turquety, S.: Aerosol-radiation interaction modelling using online coupling between the WRF 3.7.1 meteorological model and the CHIMERE 2016 chemistry-transport model, through the OASIS3-MCT coupler, Geosci. Model Dev., 10, 927-944, https://doi.org/10.5194/gmd-10-927-2017, 2017.

Brunner, D., Savage, N., Jorba, O., Eder, B., Giordano, L., Badia, A., Balzarini, A., Baró, R., Bianconi, R., Chemel, C., Curci, G., Forkel, R., Jiménez-Guerrero, P., Hirtl, M., Hodzic, A., Honzak, 
L., Im, U., Knote, C., Makar, P., Manders-Groot, A., van Meijgaard, E., Neal, L., Pérez, J. L., Pirovano, G., San Jose, R., Schröder, W., Sokhi, R. S., Syrakov, D., Torian, A., Tuccella, P., Werhahn, J., Wolke, R., Yahya, K., Zabkar, R., Zhang, Y., Hogrefe, C., and Galmarini, S.: Comparative analysis of meteorological performance of coupled chemistry-meteorology models in the context of AQMEII phase 2, Atmos. Environ., 115, 470-498, https://doi.org/10.1016/j.atmosenv.2014.12.032, 2015.

Byun, D. W. and Ching, J. K. S.: Science algorithms of the EPA Models-3 Community Multiscale Air Quality (CMAQ) modeling system, US Environmental Protection Agency Report EPA/600/R-99/030, Research Triangle Park, NC, 1999.

Carmichael, G. R., Calori, G., Hayami, H., Uno, I., Cho, S. Y., Engardt, M., Kim, S., Ichikawa, Y., Ikeda, Y., Ueda, H., and Amann, M.: The MICS-Asia study: model intercomparison of long-range transport and sulfur deposition in East Asia, Atmos. Environ., 36, 175-199, https://doi.org/10.1023/A:1012291200633, 2002.

Carmichael, G., Sakurai, T., Streets, D., Hozumi, Y., Ueda, H., Park, S., Fung, C., Han, Z., Kajino, M., and Engardt, M.: MICS-Asia II: The model intercomparison study for Asia Phase II methodology and overview of findings, Atmos. Environ., 42, 3468-3490, https://doi.org/10.1016/j.atmosenv.2007.04.007, 2008.

Carmichael, G. R., Adhikary, B., Kulkarni, S., D’Allura, A., Tang, Y., Streets, D., Zhang, Q., Bond, T. C., Ramanathan, V., Jamroensan, A., and Marrapu, P.: Asian Aerosols: Current and Year 2030 Distributions and Implications to Human Health and Regional Climate Change, Environ. Sci. Technol., 43, 5811-5817, https://doi.org/10.1021/es8036803, 2009.

Carter, W. P. L.: Documentation of the SAPRC-99 chemical mechanism for VOC reactivity assessment, Final Report to California Air Resources Board Contract 92-329 and Contract 95-308, Air Pollution Research Center and College of Engineering Center for Environmental Research and Technology, University of California Riverside, California, 2000

Chen, D., Wang, Y., McElroy, M. B., He, K., Yantosca, R. M., and Le Sager, P.: Regional CO pollution and export in China simulated by the high-resolution nested-grid GEOS-Chem model, Atmos. Chem. Phys., 9, 3825-3839, https://doi.org/10.5194/acp-93825-2009, 2009.

Chen, D., Liu, Z., Fast, J., and Ban, J.: Simulations of sulfatenitrate-ammonium (SNA) aerosols during the extreme haze events over northern China in October 2014, Atmos. Chem. Phys., 16, 10707-10724, https://doi.org/10.5194/acp-16-107072016, 2016.

Chen, L., Zhang, M., and Wang, Y.: Model analysis of urbanization impacts on boundary layer meteorology under hot weather conditions: a case study of Nanjing, China, Theoret. Appl. Climatol., 125, 713-728, https://doi.org/10.1007/s00704-015-1535-6, 2016.

Chen, L., Zhang, M., Zhu, J., and Skorokhod, A.: Model analysis of soil dust impacts on the boundary layer meteorology and air quality over East Asia in April 2015, Atmos. Res., 187, 42-56, https://doi.org/10.1016/j.atmosres.2016.12.008, 2017.

Chen, L., Zhang, M. G., Zhu, J., Wang, Y. W., and Skorokhod, A.: Modeling impacts of urbanization and urban heat island mitigation on boundary layer meteorology and air quality in Beijing under different weather conditions, J. Geophys. Res.-Atmos., 123, 4323-4344, https://doi.org/10.1002/2017JD027501, 2018.
Chen, L., Zhu, J., Liao, H., Gao, Y., Qiu, Y., Zhang, M., Liu, Z., Li, N., and Wang, Y.: Assessing the formation and evolution mechanisms of severe haze pollution in the Beijing-Tianjin-Hebei region using process analysis, Atmos. Chem. Phys., 19, 1084510864, https://doi.org/10.5194/acp-19-10845-2019, 2019.

Chin, M., Rood, R. B., Lin, S.-J., Müller, J.-F., and Thompson, A. M.: Atmospheric sulfur cycle simulated in the global model GOCART: Model description and global properties, J. Geophys. Res.-Atmos., 105, 24671-24687, https://doi.org/10.1029/2000jd900384, 2000.

Chin, M., Ginoux, P., Kinne, S., Torres, O., Holben, B. N., Duncan, B. N., Martin, R. V., Logan, J. A., Higurashi, A., and Nakajima, T.: Tropospheric aerosol optical thickness from the GOCART model and comparisons with satellite and Sun photometer measurements, J. Atmos. Sci., 59, 461-483, 2002.

Clarke, A. D., Owens, S. R., and Zhou, J. C.: An ultrafine seasalt flux from breaking waves: Implications for cloud condensation nuclei in the remote marine atmosphere, J. Geophys. Res.Atmos, 111, D06202, https://doi.org/10.1029/2005JD006565, 2006.

Cowan, T., Cai, W., Purich, A., Rotstayn, L., and England, M. H.: Forcing of anthropogenic aerosols on temperature trends of the sub-thermocline southern Indian Ocean, Sci. Rep., 3, 2245, https://doi.org/10.1038/srep02245, 2013.

Diehl, T., Heil, A., Chin, M., Pan, X., Streets, D., Schultz, M., and Kinne, S.: Anthropogenic, biomass burning, and volcanic emissions of black carbon, organic carbon, and SO2 from 1980 to 2010 for hindcast model experiments, Atmos. Chem. Phys. Discuss., 12, 24895-24954, https://doi.org/10.5194/acpd-12-248952012, 2012.

Ding, A. J., Huang, X., Nie, W., Sun, J. N., Kerminen, V. M., Petäjä, T., Su, H., Cheng, Y. F., Yang, X. Q., Wang, M. H., Chi, X. G., Wang, J. P., Virkkula, A., Guo, W. D., Yuan, J., Wang, S. Y., Zhang, R. J., Wu, Y. F., Song, Y., Zhu, T., Zilitinkevich, S., Kulmala, M., and Fu, C. B.: Enhanced haze pollution by black carbon in megacities in China, Geophys. Res. Lett., 43, 2873-2879, https://doi.org/10.1002/2016g1067745, 2016.

Du, H., Kong, L., Cheng, T., Chen, J., Du, J., Li, L., Xia, X., Leng, C., and Huang, G.: Insights into summertime haze pollution events over Shanghai based on online water-soluble ionic composition of aerosols, Atmos. Environ., 45, 5131-5137, 2011.

Fan, Q., Lan, J., Liu, Y., Wang, X., Chan, P., Hong, Y., Feng, Y., Liu, Y., Zeng, Y., and Liang, G.: Process analysis of regional aerosol pollution during spring in the Pearl River Delta region, China, Atmos. Environ., 122, 829-838, https://doi.org/10.1016/j.atmosenv.2015.09.013, 2015.

Foroutan, H., Young, J., Napelenok, S., Ran, L., Appel, K. W., Gilliam, R. C., and Pleim, J. E.: Development and evaluation of a physics-based windblown dust emission scheme implemented in the CMAQ modeling system, J. Adv. Model. Earth Sys., 9, 585-608, https://doi.org/10.1002/2016ms000823, 2017.

Fountoukis, C. and Nenes, A.: ISORROPIA II: a computationally efficient thermodynamic equilibrium model for $\mathrm{K}^{+}$ $\mathrm{Ca}^{2+}-\mathrm{Mg}^{2+}-\mathrm{NH}_{4}^{+}-\mathrm{Na}^{+}-\mathrm{SO}_{4}^{2-}-\mathrm{NO}_{3}^{-}-\mathrm{Cl}^{-}-\mathrm{H}_{2} \mathrm{O}$ aerosols, Atmos. Chem. Phys., 7, 4639-4659, https://doi.org/10.5194/acp-74639-2007, 2007.

Fu, J., Jang, C., Streets, D., Li, Z., Kwok, R., Park, R., and Han, Z.: MICS-Asia II: Modeling gaseous pollutants and evaluating an advanced modeling system over East Asia, Atmos. Environ., 
42, 3571-3583, https://doi.org/10.1016/j.atmosenv.2007.07.058, 2008.

Fu, J. S., Hsu, N. C., Gao, Y., Huang, K., Li, C., Lin, N.-H., and Tsay, S.-C.: Evaluating the influences of biomass burning during 2006 BASE-ASIA: a regional chemical transport modeling, Atmos. Chem. Phys., 12, 3837-3855, https://doi.org/10.5194/acp12-3837-2012, 2012.

Fu, Q., Zhuang, G., Wang, J., Xu, C., Huang, K., Li, J., Hou, B., Lu, T., and Streets, D. G.: Mechanism of formation of the heaviest pollution episode ever recorded in the Yangtze River Delta, China, Atmos. Environ. 42, 2023-2036, 2008.

Fu, X., Wang, S. X., Chang, X., Cai, S. Y., Xing, J., and Hao, J. M.: Modeling analysis of secondary inorganic aerosols over China: pollution characteristics, and meteorological and dust impacts, Sci. Rep., 6, 35992, https://doi.org/10.1038/srep35992, 2016.

Gao, M., Guttikunda, S. K., Carmichael, G. R., Wang, Y., Liu, Z., Stanier, C. O., Saide, P. E., and Yu, M.: Health impacts and economic losses assessment of the 2013 severe haze event in Beijing area, Sci. Total Environ., 511, 553-561, https://doi.org/10.1016/j.scitotenv.2015.01.005, 2015.

Gao, M., Han, Z., Liu, Z., Li, M., Xin, J., Tao, Z., Li, J., Kang, J.-E., Huang, K., Dong, X., Zhuang, B., Li, S., Ge, B., Wu, Q., Cheng, Y., Wang, Y., Lee, H.-J., Kim, C.-H., Fu, J. S., Wang, T., Chin, M., Woo, J.-H., Zhang, Q., Wang, Z., and Carmichael, G. R.: Air quality and climate change, Topic 3 of the Model InterComparison Study for Asia Phase III (MICS-Asia III) - Part 1: Overview and model evaluation, Atmos. Chem. Phys., 18, 48594884, https://doi.org/10.5194/acp-18-4859-2018, 2018.

Gao, Y., Zhao, C., Liu, X., Zhang, M., and Leung, L. R.: WRFChem simulations of aerosols and anthropogenic aerosol radiative forcing in East Asia, Atmos. Environ., 92, 250-266, https://doi.org/10.1016/j.atmosenv.2014.04.038, 2014.

Gao, Y., Zhang, M., Liu, Z., Wang, L., Wang, P., Xia, X., Tao, M., and Zhu, L.: Modeling the feedback between aerosol and meteorological variables in the atmospheric boundary layer during a severe fog-haze event over the North China Plain, Atmos. Chem. Phys., 15, 4279-4295, https://doi.org/10.5194/acp15-4279-2015, 2015.

Gao, Y., Zhang, M., Liu, X., and Wang, L.: Change in diurnal variations of meteorological variables induced by anthropogenic aerosols over the North China Plain in summer 2008, Theoret. Appl. Climatol., 124, 103-118, https://doi.org/10.1007/s00704015-1403-4, 2016.

Gillette, D. A. and Passi, R.: Modeling Dust Emission Caused by Wind Erosion, J. Geophys. Res.-Atmos., 93, 14233-14242, 1988.

Ginoux, P., Chin, M., Tegen, I., Prospero, J. M., Holben, B., Dubovik, O., and Lin, S. J.: Sources and distributions of dust aerosols simulated with the GOCART model, J. Geophys. Res.Atmos., 106, 20255-20273, 2001.

Gong, S. L.: A parameterization of sea-salt aerosol source function for sub- and super-micron particles, Global Biogeochem. Cy., 17, 1097, https://doi.org/10.1029/2003GB002079, 2003.

Grell, G. A., Peckham, S. E., Schmitz, R., McKeen, S. A., Frost, G., Skamarock, W. C., and Eder, B.: Fully coupled "online" chemistry within the WRF model, Atmos. Environ., 39, 6957-6975, https://doi.org/10.1016/j.atmosenv.2005.04.027, 2005.

Guenther, A., Karl, T., Harley, P., Wiedinmyer, C., Palmer, P. I., and Geron, C.: Estimates of global terrestrial isoprene emissions using MEGAN (Model of Emissions of Gases and Aerosols from Nature), Atmos. Chem. Phys., 6, 3181-3210, https://doi.org/10.5194/acp-6-3181-2006, 2006.

Hall, D.: Environmental change, protest, and havens of environmental degradation: Evidence from Asia, Global Environ. Polit., 2, 20-28, https://doi.org/10.1162/15263800260047808, 2002.

Han, X., Zhang, M., Liu, X., Steven, G., Xin, J., and Wang, L.: Development of RAMS-CMAQ to simulate aerosol optical depth and aerosol direct radiative forcing and its application to East Asia, Atmos. Ocean. Sci. Lett., 2, 368-375, https://doi.org/10.1080/16742834.2009.11446831, 2009.

Han, X., Zhang, M., Tao, J., Wang, L., Gao, J., Wang, S., and Chai, F.: Modeling aerosol impacts on atmospheric visibility in Beijing with RAMS-CMAQ, Atmos. Environ., 72, 177-191, https://doi.org/10.1016/j.atmosenv.2013.02.030, 2013.

Han, X., Zhang, M., Gao, J., Wang, S., and Chai, F.: Modeling analysis of the seasonal characteristics of haze formation in Beijing, Atmos. Chem. Phys., 14, 10231-10248, https://doi.org/10.5194/acp-14-10231-2014, 2014.

Han, X., Zhu, L., Wang, S., Meng, X., Zhang, M., and Hu, J.: Modeling study of impacts on surface ozone of regional transport and emissions reductions over North China Plain in summer 2015, Atmos. Chem. Phys., 18, 12207-12221, https://doi.org/10.5194/acp-18-12207-2018, 2018.

Han, Z., Sakurai, T., Ueda, H., Carmichael, G., Streets, D., Hayami, H., Wang, Z., Holloway, T., Engardt, M., and Hozumi, Y.: MICS-Asia II: Model intercomparison and evaluation of ozone and relevant species, Atmos. Environ., 42, 3491-3509, https://doi.org/10.1016/j.atmosenv.2007.07.031, 2008.

Han, Z. W., Ueda, H., Matsuda, K., Zhang, R. J., Arao, K., Kanai, Y., and Hasome, H.: Model study on particle size segregation and deposition during Asian dust events in March 2002, J. Geophys. Res.-Atmos., 109, D19205, https://doi.org/10.1029/2004jd004920, 2004.

Hayami, H., Sakurai, T., Han, Z., Ueda, H., Carmichael, G., Streets, D., Holloway, T., Wang, Z., Thongboonchoo, N., and Engardt, M.: MICS-Asia II: Model intercomparison and evaluation of particulate sulfate, nitrate and ammonium, Atmos. Environ., 42, 3510-3527, https://doi.org/10.1016/j.atmosenv.2007.08.057, 2008.

Holben, B. N., Eck, T. F., Slutsker, I., Tanre, D., Buis, J. P., Setzer, A., Vermote, E., Reagan, J. A., Kaufman, Y. J., Nakajima, T., Lavenu, F., Jankowiak, I., and Smirnov, A.: AERONET - A federated instrument network and data archive for aerosol characterization, Remote Sens. Environ., 66, 1-16, https://doi.org/10.1016/S0034-4257(98)00031-5, 1998.

Holloway, T., Sakurai, T., Han, Z., Ehlers, S., Spak, S., Horowitz, L., Carmichael, G., Streets, D., Hozumi, Y., and Ueda, H.: MICS-Asia II: Impact of global emissions on regional air quality in Asia, Atmos. Environ., 42, 3543-3561, https://doi.org/10.1016/j.atmosenv.2007.10.022, 2008.

Hong, C., Zhang, Q., He, K., Guan, D., Li, M., Liu, F., and Zheng, B.: Variations of China's emission estimates: response to uncertainties in energy statistics, Atmos. Chem. Phys., 17, 1227-1239, https://doi.org/10.5194/acp-17-1227-2017, 2017.

Huang, X., Song, Y., Li, M., Li, J., Huo, Q., Cai, X., Zhu, T., Hu, M., and Zhang, H.: A high-resolution ammonia emission inventory in China, Global Biogeochem. Cy., 26, GB1030, https://doi.org/10.1029/2011GB004161, 2012. 
Huang, X., Song, Y., Zhao, C., Li, M., Zhu, T., Zhang, Q., and Zhang, X.: Pathways of sulfate enhancement by natural and anthropogenic mineral aerosols in China, J. Geophys. Res.-Atmos., 119, 14165-14179, https://doi.org/10.1002/2014JD022301, 2014.

Huang, X., Wang, Z., and Ding, A.: Impact of Aerosol-PBL Interaction on Haze Pollution: Multiyear Observational Evidences in North China, Geophys. Res. Lett., 45, 8596-8603, https://doi.org/10.1029/2018g1079239, 2018.

Ikeda, K., Yamaji, K., Kanaya, Y., Taketani, F., Pan, X., Komazaki, Y., Kurokawa, J.-I., and Ohara, T.: Sensitivity analysis of source regions to $\mathrm{PM}_{2.5}$ concentration at Fukue Island, Japan, J. Air Waste Manage. Assoc., 64, 445-452, 10.1080/10962247.2013.845618, 2013.

Itahashi, S., Uno, I., Irie, H., Kurokawa, J.-I., and Ohara, T.: Regional modeling of tropospheric $\mathrm{NO}_{2}$ vertical column density over East Asia during the period 2000-2010: comparison with multisatellite observations, Atmos. Chem. Phys., 14, 3623-3635, https://doi.org/10.5194/acp-14-3623-2014, 2014.

Im, U.: Impact of sea-salt emissions on the model performance and aerosol chemical composition and deposition in the East Mediterranean coastal regions, Atmos. Environ., 75, 329-340, 2013.

Jaeglé, L., Quinn, P. K., Bates, T. S., Alexander, B., and Lin, J.-T.: Global distribution of sea salt aerosols: new constraints from in situ and remote sensing observations, Atmos. Chem. Phys., 11, 3137-3157, https://doi.org/10.5194/acp-11-3137-2011, 2011.

Janssens-Maenhout, G., Crippa, M., Guizzardi, D., Dentener, F., Muntean, M., Pouliot, G., Keating, T., Zhang, Q., Kurokawa, J., Wankmüller, R., Denier van der Gon, H., Kuenen, J. J. P., Klimont, Z., Frost, G., Darras, S., Koffi, B., and Li, M.: HTAP_v2.2: a mosaic of regional and global emission grid maps for 2008 and 2010 to study hemispheric transport of air pollution, Atmos. Chem. Phys., 15, 11411-11432, https://doi.org/10.5194/acp-15-11411-2015, 2015.

Jimenez, P., Baldasano, J. M., and Dabdub, D.: Comparison of photochemical mechanisms for air quality modeling, Atmos. Environ., 37, 4179-4194, https://doi.org/10.1016/S13522310(03)00567-3, 2003

Kajino, M., Inomata, Y., Sato, K., Ueda, H., Han, Z., An, J., Katata, G., Deushi, M., Maki, T., Oshima, N., Kurokawa, J., Ohara, T., Takami, A., and Hatakeyama, S.: Development of the RAQM2 aerosol chemical transport model and predictions of the Northeast Asian aerosol mass, size, chemistry, and mixing type, Atmos. Chem. Phys., 12, 11833-11856, https://doi.org/10.5194/acp-12-11833-2012, 2012.

Kajino, M., Deushi, M., Sekiyama, T. T., Oshima, N., Yumimoto, K., Tanaka, T. Y., Ching, J., Hashimoto, A., Yamamoto, T., Ikegami, M., Kamada, A., Miyashita, M., Inomata, Y., Shima, S., Adachi, K., Zaizen, Y., Igarashi, Y., Ueda, H., Maki, T., and Mikami, M.: NHM-Chem, the Japan MeteorologicalAgency's regional meteorology - chemistry model (v1.0): model description and aerosol representations, Geosci. Model Dev. Discuss., https://doi.org/10.5194/gmd-2018-128, 2018.

Kang, J. Y., Yoon, S. C., Shao, Y., and Kim, S. W.: Comparison of vertical dust flux by implementing three dust emission schemes in WRF/Chem, J. Geophys. Res., 116, D09202, https://doi.org/10.1029/2010JD014649, 2011.
Kelly, J. T., Bhave, P. V., Nolte, C. G., Shankar, U., and Foley, K. M.: Simulating emission and chemical evolution of coarse sea-salt particles in the Community Multiscale Air Quality (CMAQ) model, Geosci. Model Dev., 3, 257-273, https://doi.org/10.5194/gmd-3-257-2010, 2010.

Kiley, C. M., Fuelberg, H. E., Palmer, P. I., Allen, D. J., Carmichael, G. R., Jacob, D. J., Mari, C., Pierce, R. B., Pickering, K. E., Tang, Y., Wild, O., Fairlie, T. D., Logan, J. A., Sachse, G. W., Shaack, T. K., and Streets, D. G.: An intercomparison and evaluation of aircraft-derived and simulated CO from seven chemical transport models during the TRACE-P experiment, J. Geophys. Res.-Atmos., 108, 8819, https://doi.org/10.1029/2002jd003089, 2003.

Kim, S. W., Heckel, A., Frost, G. J., Richter, A., Gleason, J., Burrows, J. P., McKeen, S., Hsie, E. Y., Granier, C., and Trainer, M. $\mathrm{NO}_{2}$ columns in the western United States observed from space and simulated by a regional chemistry model and their implications for $\mathrm{NO}_{x}$ emissions, J. Geophys. Res.-Atmos., 114, D11301, https://doi.org/10.1029/2008JD011343, 2009.

Kim, Y., Couvidat, F., Sartelet, K., and Seigneur, C.: Comparison of different gas-phase mechanisms and aerosol modules for simulating particulate matter formation, J. Air Waste Manage. Assoc, 61, 1218-1226, https://doi.org/10.1080/10473289.2011.603999, 2011.

Kong, L., Tang, X., Zhu, J., Wang, Z., Fu, J. S., Wang, X., Itahashi, S., Yamaji, K., Nagashima, T., Lee, H.-J., Kim, C.-H., Lin, C.-Y., Chen, L., Zhang, M., Tao, Z., Li, J., Kajino, M., Liao, H., Sudo, K., Wang, Y., Pan, Y., Tang, G., Li, M., Wu, Q., Ge, B., and Carmichael, G. R.: Evaluation and uncertainty investigation of the $\mathrm{NO}_{2}, \mathrm{CO}$ and $\mathrm{NH}_{3}$ modeling over China under the framework of MICS-Asia III, Atmos. Chem. Phys. Discuss., https://doi.org/10.5194/acp-2018-1158, in review, 2019.

Kong, X., Forkel, R., Sokhi, R. S., Suppan, P., Baklanov, A., Gauss, M., Brunner, D., Baro, R., Balzarini, A., Chemel, C., Curci, G., Jimenez-Guerrero, P., Hirtl, M., Honzak, L., Im, U., Perez, J. L., Pirovano, G., Jose, R. S., Schlunzen, K. H., Tsegas, G., Tuccella, P., Werhahn, J., Zabkar, R., and Galmarini, S.: Analysis of meteorology-chemistry interactions during air pollution episodes using online coupled models within AQMEII phase-2, J. Atmos. Environ., 115, 527-540, https://doi.org/10.1016/j.atmosenv.2014.09.020, 2015.

Kurokawa, J., Ohara, T., Morikawa, T., Hanayama, S., JanssensMaenhout, G., Fukui, T., Kawashima, K., and Akimoto, H. Emissions of air pollutants and greenhouse gases over Asian regions during 2000-2008: Regional Emission inventory in ASia (REAS) version 2, Atmos. Chem. Phys., 13, 11019-11058, https://doi.org/10.5194/acp-13-11019-2013, 2013.

Lam, Y. F., Fu, J. S., Wu, S., and Mickley, L. J.: Impacts of future climate change and effects of biogenic emissions on surface ozone and particulate matter concentrations in the United States, Atmos. Chem. Phys., 11, 4789-4806, https://doi.org/10.5194/acp-11-4789-2011, 2011.

Lee, D. G., Lee, Y. M., Jang, K. W., Yoo, C., Kang, K. H., Lee, J. H., Jung, S. W., Park, J. M., Lee, S. B., Han, J. S., Hong, J. H., and Lee, S. J.: Korean national emissions inventory system and 2007 air pollutant emissions, Asian J. Atmos. Environ., 5, 278-291, 2011.

Li, J., Wang, Z., Zhuang, G., Luo, G., Sun, Y., and Wang, Q.: Mixing of Asian mineral dust with anthropogenic pol- 
lutants over East Asia: a model case study of a superduststorm in March 2010, Atmos. Chem. Phys., 12, 7591-7607, https://doi.org/10.5194/acp-12-7591-2012, 2012

Li, J., Du, H., Wang, Z., Sun, Y., Yang, W., Li, J., Tang, X., and Fu, P.: Rapid formation of a severe regional winter haze episode over a mega-city cluster on the North China Plain, Environ. Pollut., 223, 605-615, https://doi.org/10.1016/j.envpol.2017.01.063, 2017.

Li, J., Nagashima, T., Kong, L., Ge, B., Yamaji, K., Fu, J. S., Wang, X., Fan, Q., Itahashi, S., Lee, H.-J., Kim, C.-H., Lin, C.-Y., Zhang, M., Tao, Z., Kajino, M., Liao, H., Li, M., Woo, J.-H., Kurokawa, J.-I., Wu, Q., Akimoto, H., Carmichael, G. R., and Wang, Z.: Model evaluation and inter-comparison of surfacelevel ozone and relevant species in East Asia in the context of MICS-Asia phase III Part I: overview, Atmos. Chem. Phys. Discuss., https://doi.org/10.5194/acp-2018-1283, in review, 2019.

Li, K., Liao, H., Mao, Y., and Ridley, D. A.: Source sector and region contributions to concentration and direct radiative forcing of black carbon in China, Atmos. Environ., 124, 351-366, https://doi.org/10.1016/j.atmosenv.2015.06.014, 2016a.

Li, K., Liao, H., Zhu, J., and Moch, J. M.: Implications of RCP emissions on future $\mathrm{PM}_{2.5}$ air quality and direct radiative forcing over China, J. Geophys. Res.-Atmos., 121, 12985-13008, https://doi.org/10.1002/2016jd025623, 2016b.

Li, M., Zhang, Q., Kurokawa, J.-I., Woo, J.-H., He, K., Lu, Z., Ohara, T., Song, Y., Streets, D. G., Carmichael, G. R., Cheng, Y., Hong, C., Huo, H., Jiang, X., Kang, S., Liu, F., Su, H., and Zheng, B.: MIX: a mosaic Asian anthropogenic emission inventory under the international collaboration framework of the MICS-Asia and HTAP, Atmos. Chem. Phys., 17, 935-963, https://doi.org/10.5194/acp-17-935-2017, 2017.

Li, Y., An, J., and Gultepe, I.: Effects of additional HONO sources on visibility over the North China Plain, Adv. Atmos. Sci., 31, 1221-1232, https://doi.org/10.1007/s00376-014-4019-1, 2014.

Liao, H., Chen, W.-T., and Seinfeld, J. H.: Role of climate change in global predictions of future tropospheric ozone and aerosols, J. Geophys. Res., 111, D12304, https://doi.org/10.1029/2005jd006852, 2006.

Lin, C. Y., Zhao, C., Liu, X., Lin, N. H., and Chen, W. N.: Modelling of long-range transport of Southeast Asia biomass-burning aerosols to Taiwan and their radiative forcings over East Asia, Tellus B, 66, 23733, https://doi.org/10.3402/tellusb.v66.23733, 2014.

Lin, Y., Zou, J., Yang, W., and Li, C. Q: A review of recent advances in research on $\mathrm{PM}_{2.5}$ in China, Int. J. Environ. Res. Publ. Health, 15, 438, https://doi.org/10.3390/ijerph15030438, 2018.

Liu, X. G., Li, J., Qu, Y., Han, T., Hou, L., Gu, J., Chen, C., Yang, Y., Liu, X., Yang, T., Zhang, Y., Tian, H., and Hu, M.: Formation and evolution mechanism of regional haze: a case study in the megacity Beijing, China, Atmos. Chem. Phys., 13, 4501-4514, https://doi.org/10.5194/acp-13-4501-2013, 2013.

Liu, Y. M., Zhang, S. T., Fan, Q., Wu, D., Chan, P. W., Wang, X. M., Fan, S. J., Feng, Y. R., and Hong, Y. Y.: Accessing the Impact of Sea-Salt Emissions on Aerosol Chemical Formation and Deposition over Pearl River Delta, China, Aerosol Air Qual. Res., 15, 2232-2245, 2015.

Lohmann, U. and Diehl, K.: Sensitivity studies of the importance of dust ice nuclei for the indirect aerosol effect on stratiform mixed-phase clouds, J. Atmos. Sci., 63, 968-982, https://doi.org/10.1175/JAS3662.1, 2006.

Lu, Z., Zhang, Q., and Streets, D. G.: Sulfur dioxide and primary carbonaceous aerosol emissions in China and India, 1996-2010, Atmos. Chem. Phys., 11, 9839-9864, https://doi.org/10.5194/acp-11-9839-2011, 2011.

Luecken, D. J., Phillips, S., Sarwar, G., and Jang, C.: Effects of using the CB05 vs. SAPRC99 vs. CB4 chemical mechanism on model predictions: ozone and gas-phase photochemical precursor concentrations, Atmos. Environ., 42, 5805-5820, https://doi.org/10.1016/j.atmosenv.2007.08.056, 2008.

Luo, G. and Wang, Z. F.: A global environmental atmospheric transport model (GEATM): Model Description and validation (in Chinese), Chinese J. Atmos. Sci., 30, 504-518, https://doi.org/10.3878/j.issn.1006-9895.2006.03.13, 2006.

Makar, P. A., Moran, M. D., Zheng, Q., Cousineau, S., Sassi, M., Duhamel, A., Besner, M., Davignon, D., Crevier, L.-P., and Bouchet, V. S.: Modelling the impacts of ammonia emissions reductions on North American air quality, Atmos. Chem. Phys., 9, 7183-7212, https://doi.org/10.5194/acp-9-7183-2009, 2009.

Mann, G. W., Carslaw, K. S., Reddington, C. L., Pringle, K. J., Schulz, M., Asmi, A., Spracklen, D. V., Ridley, D. A., Woodhouse, M. T., Lee, L. A., Zhang, K., Ghan, S. J., Easter, R. C., Liu, X., Stier, P., Lee, Y. H., Adams, P. J., Tost, H., Lelieveld, J., Bauer, S. E., Tsigaridis, K., van Noije, T. P. C., Strunk, A., Vignati, E., Bellouin, N., Dalvi, M., Johnson, C. E., Bergman, T., Kokkola, H., von Salzen, K., Yu, F., Luo, G., Petzold, A., Heintzenberg, J., Clarke, A., Ogren, J. A., Gras, J., Baltensperger, U., Kaminski, U., Jennings, S. G., O’Dowd, C. D., Harrison, R. M., Beddows, D. C. S., Kulmala, M., Viisanen, Y., Ulevicius, V., Mihalopoulos, N., Zdimal, V., Fiebig, M., Hansson, H.-C., Swietlicki, E., and Henzing, J. S.: Intercomparison and evaluation of global aerosol microphysical properties among AeroCom models of a range of complexity, Atmos. Chem. Phys., 14, 4679-4713, https://doi.org/10.5194/acp-14-4679-2014, 2014.

Monahan, E. C. and Muircheartaigh, I. O.: Optimal Power-Law Description of Oceanic Whitecap Coverage Dependence on Wind Speed, J. Phys. Oceanogr., 10, 2094-2099, https://doi.org/10.1175/15200485(1980)010<2094:OPLDOO>2.0.CO;2, 1980.

Moya, M., Pandis, S. N., and Jacobson, M. Z.: Is the size distribution of urban aerosols determined by thermodynamic equilibrium? An application to Southern California, Atmos. Environ., 36, 2349-2365, 2002.

Murphy, B. N. and Pandis, S. N.: Simulating the Formation of Semivolatile Primary and Secondary Organic Aerosol in a Regional Chemical Transport Model, Environ. Sci. Technol., 43, 4722-4728, 2009.

Nagashima, T., Sudo, K., Akimoto, H., Kurokawa, J., and Ohara, T.: Long-term change in the source contribution to surface ozone over Japan, Atmos. Chem. Phys., 17, 8231-8246, https://doi.org/10.5194/acp-17-8231-2017, 2017.

Nam, J., Wang, Y., Luo, C., and Chu, D. A.: Trans-Pacific transport of Asian dust and CO: accumulation of biomass burning $\mathrm{CO}$ in the subtropics and dipole structure of transport, Atmos. Chem. Phys., 10, 3297-3308, https://doi.org/10.5194/acp10-3297-2010, 2010.

Nenes, A., Pandis, S. N., and Pilinis, C.: ISORROPIA: A new thermodynamic equilibrium model for multiphase multi- 
component inorganic aerosols, Aquat. Geochem., 4, 123-152, https://doi.org/10.1023/A:1009604003981, 1998.

Nolte, C. G., Gilliland, A. B., Hogrefe, C., and Mickley, L. J.: Linking global to regional models to assess future climate impacts on surface ozone levels in the United States, J. Geophys. Res., 113, D14307, https://doi.org/10.1029/2007jd008497, 2008.

Pan, Y., Zhang, Y., and Sarwar, G.: Impact of gas-phase chemistry on WRF/CHEM predictions of $\mathrm{O}_{3}$ and $\mathrm{PM}_{2.5}$ : Mechanism implementation and comparative evaluation, 7th annual CMAS conference, Chapel Hill, North Carolina, 2008.

Park, S. Y., Lee, H. J., Kang, J. E., Lee T., and Kim, C. H.: Aerosol radiative effects on mesoscale cloud precipitation variables over Northeast Asia during the MAPSSeoul 2015 campaign, Atmos. Environ., 172, 109-123, https://doi.org/10.1016/j.atmosenv.2017.10.044, 2018.

Petaja, T., Jarvi, L., Kerminen, V. M., Ding, A. J., Sun, J. N., Nie, W., Kujansuu, J., Virkkula, A., Yang, X. Q., Fu, C. B., Zilitinkevich, S., and Kulmala, M.: Enhanced air pollution via aerosol-boundary layer feedback in China, Sci. Rep., 6, 18998, https://doi.org/10.1038/srep18998, 2016.

Phadnis, M. J., Carmichael, G. R., Ichikawa, Y., and Hayami, H.: Evaluation of long-range transport models for acidic deposition in East Asia, J. Appl. Meteorol., 37, 1127-1142, https://doi.org/10.1175/15200450(1998)037<1127:EOLRTM>2.0.CO;2, 1998.

Pope, C. A. and Dockery, D. W.: Health Effects of Fine Particulate Air Pollution: Lines that Connect, J. Air Waste Manage. Assoc., 56, 709-742, https://doi.org/10.1080/10473289.2006.10464485, 2006.

Qiu, Y., Liao, H., Zhang, R., and Hu, J.: Simulated impacts of direct radiative effects of scattering and absorbing aerosols on surface layer aerosol concentrations in China during a heavily polluted event in February 2014, J. Geophys. Res.-Atmos., 122, 59555975, https://doi.org/10.1002/2016jd026309, 2017.

Reff, A., Bhave, P. V., Simon, H., Pace, T. G., Pouliot, G. A., Mobley, J. D., and Houyoux, M.: Emissions inventory of PM2.5 trace elements across the United States, Environ. Sci. Technol., 43, 5790-5796, https://doi.org/10.1021/es802930x, 2009.

Schell, B., Ackermann, I. J., Hass, H., Binkowski, F. S., and Ebel, A.: Modeling the formation of secondary organic aerosol within a comprehensive air quality model system, J. Geophys. Res.-Atmos., 106, 28275-28293, https://doi.org/10.1029/2001jd000384, 2001.

Seinfeld, J. H. and Pandis, S. N.: Atmospheric Chemistry and Physics: From Air Pollution to Climate Change, second edn., John Willey \& Sons, Inc., New York, 2006.

Shao, J., Chen, Q., Wang, Y., Lu, X., He, P., Sun, Y., Shah, V., Martin, R. V., Philip, S., Song, S., Zhao, Y., Xie, Z., Zhang, L., and Alexander, B.: Heterogeneous sulfate aerosol formation mechanisms during wintertime Chinese haze events: air quality model assessment using observations of sulfate oxygen isotopes in Beijing, Atmos. Chem. Phys., 19, 6107-6123, https://doi.org/10.5194/acp-19-6107-2019, 2019.

Shao, Y.,: A model for mineral dust emission, J. Geophys. Res., 106, 20239-20254, https://doi.org/10.1029/2001JD900171, 2001.

Shao, Y.,: Simplification of a dust emission scheme and comparison with data, J. Geophys. Res., 109, D10202, https://doi.org/10.1029/2003JD004372, 2004.
Singh, A. and Dey, S.: Influence of aerosol composition on visibility in megacity Delhi, Atmos. Environ., 62, 367-373, https://doi.org/10.1016/j.atmosenv.2012.08.048, 2012.

Spence, M., Clarke, A., and Buckley, R. M.: Urbanization and Growth, Commission on Growth and Development, World Bank Publications, Washington, DC, USA, 2008.

Stockwell, W. R., Middleton, P., Chang, J. S., and Tang, X.: The second generation regional acid deposition model chemical mechanism for regional air quality modeling, J. Geophys. Res.-Atmos, 95, 16343-16367, https://doi.org/10.1029/JD095iD10p16343, 1990.

Stockwell, W. R., Kirchner, F., Kuhn, M., and Seefeld, S.: A new mechanism for regional atmospheric chemistry modeling, J. Geophys. Res.-Atmos., 102, 25847-25879, https://doi.org/10.1029/97jd00849, 1997.

Stuefer, M., Freitas, S. R., Grell, G., Webley, P., Peckham, S., McKeen, S. A., and Egan, S. D.: Inclusion of ash and $\mathrm{SO}_{2}$ emissions from volcanic eruptions in WRF-Chem: development and some applications, Geosci. Model Dev., 6, 457-468, https://doi.org/10.5194/gmd-6-457-2013, 2013.

Su, L. and Fung, J. C. H.: Sensitivities of WRF-Chem to dust emission schemes and land surface properties in simulating dust cycles during springtime over East Asia, J. Geophys. Res.-Atmos., 120, 11215-11230, https://doi.org/10.1002/2015JD023446, 2015.

Su, X., Tie, X., Li, G., Cao, J., Huang, R., Feng, T., Long, $\mathrm{X}$, and $\mathrm{Xu}, \mathrm{R}$. : Effect of hydrolysis of $\mathrm{N} 2 \mathrm{O} 5$ on nitrate and ammonium formation in Beijing China: WRFChem model simulation, Sci. Total Environ., 579, 221-229, https://doi.org/10.1016/j.scitotenv.2016.11.125, 2017.

Sudo, K., Takahashi, M., Kurokawa, J., and Akimoto, H.: CHASER: A global chemical model of the troposphere-1, Model description, J. Geophys. Res.-Atmos., 107, ACH 7-1-ACH 7-20,, https://doi.org/10.1029/2001jd001113, 2002a.

Sudo, K., Takahashi, M., and Akimoto, H.: CHASER: A global chemical model of the troposphere-2, Model results and evaluation, J. Geophys. Res.-Atmos., 107, 107, 4586, https://doi.org/10.1029/2001jd001114, 2002b.

Sun, Y. L., Zhuang, G. S., Tang, A. H., Wang, Y., and An, Z. S.: Chemical characteristics of $\mathrm{PM}_{2.5}$ and $\mathrm{PM}_{10}$ in haze-fog episodes in Beijing, Environ. Sci. Technol., 40, 3148-3155, https://doi.org/10.1021/es051533g, 2006.

Sun, Y., Du, W., Fu, P., Wang, Q., Li, J., Ge, X., Zhang, Q., Zhu, C., Ren, L., Xu, W., Zhao, J., Han, T., Worsnop, D. R., and Wang, Z.: Primary and secondary aerosols in Beijing in winter: sources, variations and processes, Atmos. Chem. Phys., 16, 8309-8329, https://doi.org/10.5194/acp-16-8309-2016, $2016 \mathrm{a}$.

Sun, Y., Wang, Z., Wild, O., Xu, W., Chen, C., Fu, P., Du, W., Zhou, L., Zhang, Q., Han, T., Wang, Q., Pan, X., Zheng, H., Li, J., Guo, X., Liu, J., and Worsnop, D. R.: "APEC Blue": Secondary Aerosol Reductions from Emission Controls in Beijing, Sci. Rep., 6, 20668, https://doi.org/10.1038/srep20668, 2016 b.

Tao, Z., Santanello, J. A., Chin, M., Zhou, S., Tan, Q., Kemp, E. M., and Peters-Lidard, C. D.: Effect of land cover on atmospheric processes and air quality over the continental United States - a NASA Unified WRF (NU-WRF) model study, Atmos. Chem. Phys., 13, 6207-6226, https://doi.org/10.5194/acp13-6207-2013, 2013. 
van der Werf, G. R., Randerson, J. T., Giglio, L., Collatz, G. J., Mu, M., Kasibhatla, P. S., Morton, D. C., DeFries, R. S., Jin, Y., and van Leeuwen, T. T.: Global fire emissions and the contribution of deforestation, savanna, forest, agricultural, and peat fires (1997-2009), Atmos. Chem. Phys., 10, 11707-11735, https://doi.org/10.5194/acp-10-11707-2010, 2010.

Walcek, C. J. and Taylor, G. R.: A theoretical method for computing vertical distributions of acidity and sulfate production within cumulus clouds, J. Atmos. Sci., 43, 339-355, https://doi.org/10.1175/15200469(1986)043<0339:ATMFCV>2.0.CO;2, 1986.

Wang, C.: Impact of anthropogenic absorbing aerosols on clouds and precipitation: A review of recent progresses, Atmos. Res., 122, 237-249, https://doi.org/10.1016/j.atmosres.2012.11.005, 2013.

Wang, H., Xie, S.-P., and Liu, Q.: Comparison of Climate Response to Anthropogenic Aerosol versus Greenhouse Gas Forcing: Distinct Patterns, J. Climate, 29, 5175-5188, https://doi.org/10.1175/jcli-d-16-0106.1, 2016.

Wang, J., Wang, X., Zhang, H., Lu, F., and Hou, P.: Comparison of $\mathrm{PM}_{2.5}$ concentration and elemental compositions in two typical sites in Beijing urban area, Acta Sci. Circ., 32, 74-80, 2012.

Wang, P., Wang, H., Wang, Y. Q., Zhang, X. Y., Gong, S. L., Xue, M., Zhou, C. H., Liu, H. L., An, X. Q., Niu, T., and Cheng, Y. L.: Inverse modeling of black carbon emissions over China using ensemble data assimilation, Atmos. Chem. Phys., 16, 989-1002, https://doi.org/10.5194/acp-16-989-2016, 2016.

Wang, X., Liao, J. B., Zhang, J., Shen, C., Chen, W. H., Xia, B. C. and Wang, T. J.: A Numeric Study of Regional Climate Change Induced by Urban Expansion in the Pearl River Delta, China, J. Appl. Meteorol. Climatol., 53, 346-362, https://doi.org/10.1175/JAMC-D-13-054.1, 2014.

Wang, Y., Zhang, Q. Q., He, K., Zhang, Q., and Chai, L.: Sulfate-nitrate-ammonium aerosols over China: response to 2000-2015 emission changes of sulfur dioxide, nitrogen oxides, and ammonia, Atmos. Chem. Phys., 13, 2635-2652, https://doi.org/10.5194/acp-13-2635-2013, 2013.

Wang, Y. S., Yao, L., Wang, L. L., Liu, Z. R., Ji, D. S., Tang, G. Q., Zhang, J. K., Sun, Y., Hu, B., and Xin, J. Y.: Mechanism for the formation of the January 2013 heavy haze pollution episode over central and eastern China, Sci. China Earth Sci., 57, 14-25, https://doi.org/10.1007/s11430-013-4773-4, 2014.

Wang, Z., Maeda, T., Hayashi, M., Hsiao, L. F., and Liu, K. Y.: A nested air quality prediction modeling system for urban and regional scales: Application for high-ozone episode in Taiwan. Water Air Soil Pollut., 130, 391-396, https://doi.org/10.1023/A:1013833217916, 2001.

Wang, Z., Xie, F., Sakurai, T., Ueda, H., Han, Z., Carmichael, G., Streets, D., Engardt, M., Holloway, T., and Hayami, H.: MICS-Asia II: Model inter-comparison and evaluation of acid deposition, Atmos. Environ., 42, 3528-3542, https://doi.org/10.1016/j.atmosenv.2007.12.071, 2008.

Wang, Z., Li, J., Wang, Z., Yang, W., Tang, X., Ge, B., Yan, P., Zhu, L., Chen, X., Chen, H., Wand, W., Li, J., Liu, B., Wang, X., Wand, W., Zhao, Y., Lu, N., and Su, D.: Modeling study of regional severe hazes over mid-eastern China in January 2013 and its implications on pollution prevention and control, Sci. China Earth Sci., 57, 3-13, https://doi.org/10.1007/s11430-013-4793$0,2013$.
Wang, Z. F., Ueda, H., and Huang, M. Y.: A deflation module for use in modeling long-range transport of yellow sand over East Asia, J. Geophys. Res.-Atmos., 105, 26947-26959, 2000.

Wang, Z. F., Akimoto, H., and Uno, I.: Neutralization of soil aerosol and its impact on the distribution of acid rain over east Asia: Observations and model results, J. Geophys. Res.-Atmos., 107, 4389, https://doi.org/10.1029/2001JD001040, 2002.

Yamaji, K., Ohara, T., Uno, I., Kurokawa, J.-I., Pochanart, P., and Akimoto, H.: Future prediction of surface ozone over east Asia using Models-3 Community Multiscale Air Quality Modeling System and Regional Emission Inventory in Asia, J. Geophys. Res., 113, D08306, https://doi.org/10.1029/2007jd008663, 2008.

Yan, Z.-W., Wang, J., Xia, J.-J., and Feng, J.-M.: Review of recent studies of the climatic effects of urbanization in China, Adv. Climate Change Res., 7, 154-168, https://doi.org/10.1016/j.accre.2016.09.003, 2016.

Yang, J. H., Kang, S. C., Ji, Z. M., and Chen, D. L.: Modeling the origin of anthropogenic black carbon and its climatic effect over the Tibetan Plateau and surrounding regions, J. Geophys. Res.-Atmos., 123, 671-692, https://doi.org/10.4209/aaqr.2017.05.0156, 2018.

Yang, Y., Russell, L. M., Lou, S., Lamjiri, M. A., Liu, Y., Singh, B., and Ghan, S. J.: Changes in Sea Salt Emissions Enhance ENSO Variability, J. Climate, 29, 8575-8588, https://doi.org/10.1175/JCLI-D-16-0237.1, 2016.

Yarwood, G., Rao, S., Yocke, M., and Whitten, G. Z.: Updates to the Carbon Bond Chemical Mechanism: CB05, Final Report to the US EPA, RT-0400675, 2005.

Yue, X., Wang, H. J., Liao, H., and Fan, K.: Simulation of dust aerosol radiative feedback using the GMOD: 2, Dust climate interactions, J. Geophys. Res.-Atmos., 115, D10202, https://doi.org/10.1029/2008JD010995, 2010.

Yue, X., Unger, N., Harper, K., Xia, X., Liao, H., Zhu, T., Xiao, J., Feng, Z., and Li, J.: Ozone and haze pollution weakens net primary productivity in China, Atmos. Chem. Phys., 17, 60736089, https://doi.org/10.5194/acp-17-6073-2017, 2017.

Zaveri, R. A. and Peters, L. K.: A new lumped structure photochemical mechanism for large-scale applications, J. Geophys. Res.-Atmos, 104, 30387-30415, https://doi.org/10.1029/1999jd900876, 1999.

Zhang, B., Wang, Y., and Hao, J.: Simulating aerosol-radiationcloud feedbacks on meteorology and air quality over eastern China under severe haze conditionsin winter, Atmos. Chem. Phys., 15, 2387-2404, https://doi.org/10.5194/acp-152387-2015, 2015.

Zhang, M., Uno, I., Sugata, S., Wang, Z., Byun, D., Akimoto, H.: Numerical study of boundary layer ozone transport and photochemical production in East Asia in the wintertime, Geophys. Res. Lett., 29, 40-1-40-4, https://doi.org/10.1029/2001GL014368, 2002.

Zhang, M., Uno, I., Zhang, R., Han, Z., Wang, Z., and Pu, Y.: Evaluation of the Models-3 Community Multi-scale Air Quality (CMAQ) modeling system with observations obtained during the TRACE-P experiment: Comparison of ozone and its related species, Atmos. Environ., 40, 4874-4882, https://doi.org/10.1016/j.atmosenv.2005.06.063, 2006.

Zhang, M., Han, Z., and Zhu, L.: Simulation of atmospheric aerosols in East Asia using modeling system RAMS- 
CMAQ: Model evaluation, China Particuol., 5, 321-327, https://doi.org/10.1016/j.cpart.2007.07.002, 2007.

Zhang, R., Sun, X. S., Shi, A. J., Huang, Y. H., Yan, J., Nie, T., Yan, $\mathrm{X}$., and $\mathrm{Li}, \mathrm{X}$.: Secondary inorganic aerosols formation during haze episodes at an urban site in Beijing, China, Atmos. Environ., 177, 275-282, https://doi.org/10.1016/j.atmosenv.2017.12.031, 2018.

Zhao, C., Liu, X., Leung, L. R., Johnson, B., McFarlane, S. A., Gustafson Jr., W. I., Fast, J. D., and Easter, R.: The spatial distribution of mineral dust and its shortwave radiative forcing over North Africa: modeling sensitivities to dust emissions and aerosol size treatments, Atmos. Chem. Phys., 10, 8821-8838, https://doi.org/10.5194/acp-10-8821-2010, 2010.
Zhao, X. J., Zhao, P. S., Xu, J., Meng,, W., Pu, W. W., Dong, F., He, D., and Shi, Q. F.: Analysis of a winter regional haze event and its formation mechanism in the North China Plain, Atmos. Chem. Phys., 13, 5685-5696, https://doi.org/10.5194/acp13-5685-2013, 2013.

Zheng, B., Zhang, Q., Zhang, Y., He, K. B., Wang, K., Zheng, G. J., Duan, F. K., Ma, Y. L., and Kimoto, T.: Heterogeneous chemistry: a mechanism missing in current models to explain secondary inorganic aerosol formation during the January 2013 haze episode in North China, Atmos. Chem. Phys., 15, 2031-2049, https://doi.org/10.5194/acp-15-2031-2015, 2015.

Zhu, J., Liao, H., Mao, Y., Yang, Y., and Jiang, H.: Interannual variation, decadal trend, and future change in ozone outflow from East Asia, Atmos. Chem. Phys., 17, 3729-3747, https://doi.org/10.5194/acp-17-3729-2017, 2017. 